\title{
Remote sensing of soot carbon - Part 1: Distinguishing different absorbing aerosol species
}

\author{
G. L. Schuster ${ }^{1}$, O. Dubovik ${ }^{2}$, and A. Arola ${ }^{3}$ \\ ${ }^{1}$ NASA Langley Research Center, Hampton, VA, USA \\ ${ }^{2}$ Laboratoire d'Optique Atmosphérique, Université de Lille-1, CNRS, Villeneuve d'Ascq, France \\ ${ }^{3}$ Finnish Meteorological Institute, Kuopio, Finland \\ Correspondence to: G. L. Schuster (gregory.1.schuster@nasa.gov)
}

Received: 24 March 2015 - Published in Atmos. Chem. Phys. Discuss.: 12 May 2015

Revised: 7 December 2015 - Accepted: 22 December 2015 - Published: 11 February 2016

\begin{abstract}
We describe a method of using the Aerosol Robotic Network (AERONET) size distributions and complex refractive indices to retrieve the relative proportion of carbonaceous aerosols and free iron minerals (hematite and goethite). We assume that soot carbon has a spectrally flat refractive index and enhanced imaginary indices at the $440 \mathrm{~nm}$ wavelength are caused by brown carbon or hematite. Carbonaceous aerosols can be separated from dust in imaginary refractive index space because $95 \%$ of biomass burning aerosols have imaginary indices greater than 0.0042 at the $675-1020 \mathrm{~nm}$ wavelengths, and $95 \%$ of dust has imaginary refractive indices of less than 0.0042 at those wavelengths. However, mixtures of these two types of particles can not be unambiguously partitioned on the basis of optical properties alone, so we also separate these particles by size. Regional and seasonal results are consistent with expectations. Monthly climatologies of fine mode soot carbon are less than $1.0 \%$ by volume for West Africa and the Middle East, but the southern African and South American biomass burning sites have peak values of 3.0 and $1.7 \%$. Monthly averaged fine mode brown carbon volume fractions have a peak value of $5.8 \%$ for West Africa, $2.1 \%$ for the Middle East, $3.7 \%$ for southern Africa, and $5.7 \%$ for South America. Monthly climatologies of free iron volume fractions show little seasonal variability, and range from about 1.1 to $1.7 \%$ for coarse mode aerosols in all four study regions. Finally, our sensitivity study indicates that the soot carbon retrieval is not sensitive to the component refractive indices or densities assumed for carbonaceous and free iron aerosols, and the retrieval differs by only $15.4 \%$ when these parameters are altered from
\end{abstract}

our chosen baseline values. The total uncertainty of retrieving soot carbon mass is $\sim 50 \%$ (when uncertainty in the AERONET product and mixing state is included in the analysis).

\section{Introduction}

Soot carbon ( $\mathrm{sC}$ ) is a byproduct of combustion that is composed of aggregated graphite spheres (Andreae and Gelencsér, 2006). It is often called light absorbing carbon (LAC), black carbon (BC), refractory black carbon ( $\mathrm{rBC})$, or elemental carbon (EC) in the scientific literature (depending upon the measurement technique), but we prefer the carbonaceous aerosol definitions nicely presented by Andreae and Gelencsér (2006). Thus, the term $\mathrm{sC}$ presented here is equivalent to LAC in Bond and Bergstrom (2006) and BC or $\mathrm{rBC}$ in Bond et al. (2013). Loosely, the term EC refers to $\mathrm{sC}$ that is obtained by thermal techniques, and the term $\mathrm{BC}$ refers to $\mathrm{sC}$ that is obtained by optical techniques; the term $\mathrm{BC}$ is also used generically by the modeling community. We use the term brown carbon $(\mathrm{BrC})$ for absorbing organic matter to distinguish these particles from organic matter that does not absorb significantly at visible wavelengths (Jacobson, 1999; Kirchstetter et al., 2004; Kanakidou et al., 2005; Hoffer et al., 2006; Schnaiter et al., 2006; Sun et al., 2007; Dinar et al., 2008; Chen and Bond, 2010). However, both $\mathrm{BrC}$ and organic carbon (OC) are composed of many organic species, and the $\mathrm{BrC}$ detected in the atmosphere also contains some 
non-absorbing organic particulates as well (i.e., the scientific community has probably not isolated "pure" $\mathrm{BrC}$ ).

Atmospheric warming caused by $\mathrm{sC}$ is highly uncertain. The most recent Intergovernmental Panel on Climate Change (IPCC; Boucher et al., 2013) estimate of the sC direct radiative forcing for fossil fuel and biofuel $\mathrm{sC}$ is $+0.4 \mathrm{~W} \mathrm{~m}^{-2}$ (with an uncertainty range of +0.05 to $+0.8 \mathrm{~W} \mathrm{~m}^{-2}$ ); this estimate is based upon the AeroCom Phase II model simulations of Myhre et al. (2013a) and the scaled absorption aerosol optical depth (AAOD) findings of Bond et al. (2013). The direct effect does not capture all forcing mechanisms, however, and Bond et al. (2013) estimate that the industrial-era climate forcing associated with $\mathrm{sC}$ is $\mathrm{RF}_{\mathrm{SC}}=+1.1 \mathrm{~W} \mathrm{~m}^{-2}$, with an uncertainty range of +0.17 to $+2.1 \mathrm{~W} \mathrm{~m}^{-2}$ when all forcing mechanisms are included. Soot carbon radiative forcing is second only to $\mathrm{CO}_{2}$ radiative forcing as a contributor to global warming (Ramanathan and Carmichael, 2008; Bond et al., 2013). Finally, although $\mathrm{CO}_{2}$ radiative forcing is larger than $\mathrm{sC}$ radiative forcing $\left(\mathrm{RF}_{\mathrm{CO}_{2}}=1.8 \pm 0.19 \mathrm{~W} \mathrm{~m}^{-2}\right.$, per Myhre et al., 2013b), the range of uncertainty for $\mathrm{sC}$ forcing is much larger than the range of uncertainty for $\mathrm{CO}_{2}$ forcing.

The cooling associated with all aerosols in the IPCC fifth assessment report is $-0.35 \pm 0.5 \mathrm{~W} \mathrm{~m}^{-2}$; thus, soot carbon warming from the direct effect alone reduces aerosol cooling by about $53 \%$. This has prompted suggestions that reducing $\mathrm{sC}$ could be a viable method of mitigating global warming in the short term (Jacobson, 2010). Others have noted that non-absorbing aerosols that are co-emitted with $\mathrm{sC}$ make this difficult in practice (Bond et al., 2013).

Soot carbon warming is uncertain because modeled $\mathrm{sC}$ concentrations and the associated absorption are unconstrained by in situ measurements. The difficulty is the lack of available $\mathrm{sC}$ data. The Interagency Monitoring of Protected Visual Environments (IMPROVE) network provides routine EC measurements at the surface in the United States, but mainly in remote areas (Malm et al., 1994). Some surface measurements are also available in other parts of the world (Koch et al., 2009), but global coverage of sC concentration and absorption is not available from satellite data.

Modeled $\mathrm{sC}$ concentrations are too high by a factor of 1.6 on average over North America when compared to long-term in situ measurements at the surface (Park et al., 2003; Koch et al., 2009), and they are too high by a factor of 5 to 7.9 when compared to aircraft measurements during field campaigns over the United States, Canada, and the Pacific Ocean (Koch et al., 2009; Schwarz et al., 2010). Modeled AAOD, however, is lower than the Aerosol Robotic Network (AERONET) and Ozone Monitoring Instrument (OMI) products by a factor of 0.69 and 0.85 over North America (Koch et al., 2009) and a factor of 2-4 lower than AERONET worldwide (Sato et al., 2003). Thus, the link between $\mathrm{sC}$ emissions, sC concentrations, and AAOD is not straightforward, and the low bias in modeled AAOD over North American source regions can not be simply associated with errors in the $\mathrm{sC}$ emission inventories alone.

One problem is that $\mathrm{sC}$ is not the only absorbing aerosol in the atmosphere, as $\mathrm{BrC}$ and free iron (hematite and goethite) in dust are significant absorbers at ultraviolet through midvisible wavelengths (Kerker et al., 1979; Chen and Cahan, 1981; Hsu and Matijević, 1985; Gillespie and Lindberg, 1992; Bedidi and Cervelle, 1993; Kirchstetter et al., 2004; Sun et al., 2007; Derimian et al., 2008; Chen and Bond, 2010). Separating the absorption associated with $s C$ from the absorption associated with these other aerosols is not trivial; this is especially true for absorption at the $550 \mathrm{~nm}$ wavelength favored by many studies, since all of these aerosol species absorb at that wavelength.

Thus, there is a need for determining the relative proportions of $\mathrm{sC}, \mathrm{BrC}$, and free iron in atmospheric aerosols. Knowledge of both $\mathrm{SC}$ mixing ratios and $\mathrm{AAOD}$ are important for constraining how $\mathrm{SC}$ is transported, removed, and mixed with other aerosols in the global models. AERONET provides aerosol size distributions and complex refractive index at four wavelengths $(440,675,870$, and $1020 \mathrm{~nm})$ at hundreds of surface sites throughout the world (Holben et al., 1998, 2001; Dubovik and King, 2000; Dubovik et al., 2000). This information can be used to retrieve the relative proportions of carbonaceous aerosols and free iron minerals. Schuster et al. (2005) retrieved sC from the aerosol complex refractive index provided in the AERONET database by assuming that all aerosol absorption is associated with $\mathrm{sC}$. Arola et al. (2011) used the spectral variability of the imaginary refractive index in the AERONET database to retrieve BrC. Similarly, Li et al. (2013) used AERONET complex refractive indices to retrieve $\mathrm{SC}, \mathrm{BrC}$, and dust over Beijing. Wang et al. (2013) added single-scatter albedo as an additional constraint to these refractive index approaches. Koven and Fung (2006) used the spectral variability of the imaginary index to retrieve hematite concentrations at dust sites.

Other methods of retrieving $\mathrm{sC}$ from AERONET data include the absorption Ångström exponent (AAE) approach (Chung et al., 2012; Bahadur et al., 2012) and the Bond et al. (2013) approach. However, the AAE approach assumes that all absorbing aerosols are externally mixed (which is inconsistent with the AERONET retrieval algorithm), and it does not necessarily maintain a link to the measured radiances. The Bond et al. (2013) approach computes the AAOD for the coarse mode by using a climatological value for dust and subtracting the dust AAOD from the total AAOD to infer the sC AAOD (BrC absorption is omitted from the computation). Since the coarse mode refractive index is different from the AERONET-retrieved value, this approach does not necessarily maintain a link to the radiance field, either.

Here, we present a method of deriving column concentrations of $\mathrm{sC}$ mass and mixing ratios that are consistent with the AERONET AAODs, size distributions, and refractive indices. The method is an improvement over our previous method (Schuster et al., 2005) because it uses different 
mixtures of aerosol species for the fine mode than for the coarse mode. That is, we assume that the fine mode is dominated by carbonaceous absorbing aerosols and that the coarse mode is dominated by the free iron commonly found in mineral aerosols.

\section{Description of the AERONET product}

AERONET is a network of several hundred sun and sky scanning radiometers located at surface sites throughout the world (Holben et al., 1998, 2001, and http://aeronet.gsfc. nasa.gov). The radiometers have a narrow field of view $\left(1.2^{\circ}\right)$ and typically provide direct sun measurements in eight narrow spectral bands (nominally centered at 0.34, 0.38, 0.44, $0.50,0.675,0.87,0.94$, and $1.02 \mu \mathrm{m}$ ). The measurements are processed to provide aerosol optical depth (AOD) products in the AERONET database. The direct sun measurements are corrected for $\mathrm{NO}_{2}$ and $\mathrm{O}_{3}$ absorption using monthly climatologies from satellite records. The ESA's Scanning Imaging Absorption Spectrometer for Atmospheric Chartography (SCIAMACHY) climatology is used for the $\mathrm{NO}_{2}$ correction, and NASA's Total Ozone Mapping Spectrometer (TOMS) is used for the $\mathrm{O}_{3}$ correction (http://aeronet.gsfc.nasa.gov/new web/Documents/version2_table.pdf). Corrections for $\mathrm{CO}_{2}$, $\mathrm{CH}_{4}$, Rayleigh scattering, water vapor absorption, and the Earth-sun distance are also included in the AERONET products. Cloud screening is accomplished with the Smirnov et al. (2000) procedure. Instruments are calibrated on a 6-12 month rotation, and changes in the calibration coefficients are linearly interpolated between calibrations. Additional instrument details may be found in Holben et al. (1998) and at http: //aeronet.gsfc.nasa.gov/new_web/system_descriptions.html.

The AERONET instruments also measure sky radiances at four wavelengths $(0.44,0.675,0.87$, and $1.02 \mu \mathrm{m})$. One component of the sky radiance measurements is the almucantar scan (Nakajima et al., 1983, 1996; Kaufman et al., 1994; Holben et al., 1998), which forms the basis of the size distribution and absorption retrieval products in the AERONET database (Dubovik and King, 2000; Dubovik et al., 2002b, 2006). This scan occurs at a constant viewing zenith angle that is equal to the solar zenith angle $\left(\theta_{0}\right)$, and it includes 56 azimuth angles that vary from -180 to $180^{\circ}$ (with respect to the solar azimuth angle). The use of positive and negative azimuth angles results in many redundant scattering angles, and this redundancy is used with symmetry arguments to filter measurements that are affected by clouds and inhomogeneous aerosol plumes. Pairs of measurements with identical scattering angles must agree to within $20 \%$ to be used in a retrieval, and at least 14 angular pairs at specific angular ranges must survive for a Level 2 retrieval (Holben et al., 2006). The minimum required solar zenith angle is $50^{\circ}$ for the Level 2 products, which assures a scattering angle measurement range of at least 0 to $100^{\circ}$. Additionally, AOD is required to be greater than 0.4 at the $0.440 \mu \mathrm{m}$ wavelength for the Level 2 absorption products (i.e., complex refractive index, single-scatter albedo, AAOD). Additional screening implemented for Level 2 retrievals may be found at http://aeronet.gsfc.nasa.gov/new_web/Documents/ Quality_Control_Checklist.pdf. Throughout this paper we consider only Level 2 AERONET retrievals.

Instruments manufactured prior to 2004 utilize dual detectors in order to cover the wide dynamic range of the sun and sky measurements. The measurement protocol for these systems includes a consistency check at $\pm 6^{\circ}$ azimuth, where both detectors observe the sky. Sky radiances reported by the two sensors at this angle are required to agree to within $\pm 5 \%$ for the Level 2 inversions (Holben et al., 2006). Instruments manufactured since 2004 utilize a single detector for both the sun and sky measurements and therefore do not need this consistency check.

The microphysical model used for the advanced retrieval products is a homogeneous internal mixture of spheres and spheroids, which are dispersed throughout a uniform aerosol layer (Dubovik and King, 2000; Dubovik et al., 2002b, 2006). The size distribution and refractive index are adjusted in a forward radiation model to produce a statistically optimized solution, and the final solution accounts for measurement accuracy as well as a priori constraints (Dubovik and King, 2000; Dubovik, 2004). The retrieval provides the aerosol volume size distribution ( $\mathrm{dV} / \mathrm{dln} r)$ for 22 radii between 0.05 and $15 \mu \mathrm{m}$ (integrated over the atmospheric column) and the complex refractive index at the four scanning wavelengths. The size distributions can have any shape (i.e., lognormal distributions are not a requirement), but a priori smoothness constraints are applied to avoid unrealistically sharp oscillations, and concentrations are forced to asymptote to small values at the extreme sizes (Dubovik and King, 2000; Hashimoto et al., 2012).

The AERONET algorithm also assumes that all particles in the atmosphere have the same complex refractive index (regardless of size), which is equivalent to assuming that all particles have identical composition (and all aerosol species are internally mixed). This assumption is necessary to achieve a unique solution, and it forces the absorption to be spread over all retrieved particle sizes, even if the absorption really occurs in only the smallest particles. The repercussions of this assumption are discussed in Schuster et al. (2016).

Once an optimal size distribution and refractive index are found, they are used to compute the AAOD, AAE, singlescatter albedo $\left(\omega_{0}\right)$, and other optical parameters reported in the AERONET database. Thus, all of the almucantar retrieval products are mathematically linked by Mie theory and T-matrix theory, and we can not claim that one of these parameters is more robust than another. The AERONET product is a "package" in this sense - taken together, all of the products provide a consistent set of parameters that produce the measured radiance field. 
The advantage of computing aerosol optical properties in this way is that the retrievals are constrained to realistic values. For instance, the almucantar scan provides radiances over a limited range of scattering angles $(\theta)$, with the maximum scattering angle being twice the solar zenith angle; consequently, a significant range of scattering angles are unobserved. Thus, the inferred size distributions and refractive indices provide the correct phase functions and radiances where measurements are available (i.e., $\theta \leq 2 \times \theta_{\circ}$ ), and viable phase functions at angles where they are not available $\left(\theta>2 \times \theta_{\circ}\right)$. The resulting radiances and irradiances computed from the AERONET microphysical models compare well with independent measurements (Schuster, 2004; Garcia et al., 2008). Finally, since single-scatter albedo is computed from Mie or T-matrix theory, $\omega_{\circ} \leq 1$ for all of the retrievals in the AERONET database, and the non-physical value of $\omega_{\circ}>1$ that is sometimes observed with extinction and nephelometer measurements never occurs.

The microphysical model affects how we can interpret the data, especially the internal mixture assumption. For instance, we can not conclude that low AAEs in urban regions are attributed to external mixing of $\mathrm{sC}$ (as in Chung et al., 2012; Bahadur et al., 2012), because all aerosol species are always internally mixed in the AERONET retrieval model. Additionally, we can not assume that the component sum of the AAODs for all absorbing species equals the total AAOD, because component absorption efficiencies are not additive with internal mixtures; this is because a non-absorbing host aerosol increases the absorption cross section for all of the embedded absorbing particles (e.g., the absorption of a particle with $\mathrm{sC}$ embedded in a non-absorbing host is greater than the absorption of the isolated $\mathrm{sC}$ particle). We discuss this extensively in Schuster et al. (2016).

Likewise, we can not assign a refractive index to the coarse aerosol mode that is different from the retrieved value (as in Bond et al., 2013) without the risk of severing the link to the radiation field. The link to the radiance field is very important, as it forces AERONET to produce viable solutions that are the strength of the AERONET product. Consequently, the use of reasonable model assumptions that are not consistent with the original retrieval can produce results that are inconsistent with the radiance measurements (even if the new assumptions are more realistic than the AERONET assumptions). This lack of consistency with the AERONET retrieval model is a potential source of error in the Bond et al. (2013) approach that may or may not be significant when dust is mixed with biomass burning aerosols.

All of the AERONET retrieval products are affected by the errors associated with choosing simplified particle shapes to represent the myriad of particles in the atmosphere (although this is not the case for AOD, which is directly measured). The retrieval would undoubtedly produce different results if chain aggregates, hexagonal columns, and particles with rough surfaces were chosen as the particle shapes in the forward component of the retrieval model. Although these shapes might be more realistic than spheres and spheroids for atmospheric aerosols, the scientific community has not created computer codes that are capable of providing the single-scatter optical properties for size distributions of these particles. Consequently, biases in the retrieval products that are caused by the simplified shape assumption have not been quantified. (Simplified shapes may also be an issue for some in situ measurements that require Mie theory for calibration; e.g., optical particle sizers and nephelometer truncation corrections.)

The size distribution accuracy expected for fine mode dominated aerosols is $15-25$ percent for radii between 0.1 and $7 \mu \mathrm{m}, 25-100 \%$ otherwise. The complex refractive index is allowed to vary with wavelength in the microphysical model, but it remains constant with respect to particle size. The real refractive index is expected to be accurate to 0.04 and the imaginary refractive index accurate to $30-50 \%$ for aerosol optical thicknesses greater than 0.4 at the $0.440 \mu \mathrm{m}$ wavelength. The uncertainties are higher for coarse-modedominated aerosols such as dust and optically thin aerosols; an accuracy assessment of the AERONET retrievals can be found in Dubovik et al. (2000).

Although there have been many attempts to validate AERONET retrievals with independent measurements, few would argue that the products derived from the AERONET almucantar scans have been robustly validated. This is because the AERONET Level 2 quality-control restrictions require clear skies, solar zenith angles $\theta_{\circ} \geq 50^{\circ}$, and $\operatorname{AOD}(440)$ greater than 0.4 ; numerous occurrences of these conditions are difficult to achieve during a 6-8 week aircraft field mission. Consequently, no study thus far has provided a statistically robust comparison that quantifies the biases associated with the AERONET retrieval products.

A thorough review of the AERONET validation studies is beyond the scope of this paper, but in the following paragraphs we note some important concepts that must be kept in mind when comparing AERONET products to in situ measurements. An ideal comparison of aircraft in situ measurements with AERONET retrievals would include many tight spirals above AERONET sites during almucantar scans in conditions that are appropriate for Level 2 retrievals. The aircraft spirals should also cover all portions of the atmospheric column where aerosols are present and be numerous enough for a robust statistical analysis. Schafer et al. (2014) probably provides the most complete comparison of AERONET single-scatter albedo products to simultaneous in situ measurements obtained on board aircraft, but that study is still limited to eight comparisons. We refer readers who are interested in additional validation studies to Haywood et al. (2003), Reid et al. (2003), Reid et al. (2005a), Leahy et al. (2007), Corrigan et al. (2008), and Johnson et al. (2009). Additionally, Holben et al. compiled a nice summary of validation efforts that were available up until 2011, which can be found at http://aeronet.gsfc.nasa.gov/new_web/Documents/ DRAGON_White_Paper_A_system_of_experiment.pdf. 
AERONET provides products that represent columnintegrated values, whereas in situ instruments sample a small volume of the atmosphere. One can mount in situ instruments on board aircraft to measure aerosol properties throughout the atmospheric column, but this still requires integration of the measured profiles over the entire column. Integration of profiles is a relatively straightforward process for extrinsic parameters like size distributions and AOD, because we can sum measurements that are obtained from multiple layers of known geometric thickness. Column integration of the single-scatter albedo requires a little more thought, but it can be accomplished by computing AOD and AAOD prior to computing the column $\omega_{\circ}$. There really is not a viable method of obtaining column-integrated values for intrinsic parameters like refractive index with in situ measurements at the present time, though. We as a community should resist the temptation to compute column averages by weighting in situ measurements with extinction profiles, as the fine and coarse mode aerosols have significantly different extinction efficiencies.

Aerosol water content is another difficulty that confounds comparisons of AERONET data with in situ measurements. AERONET instruments observe the entire atmospheric column at ambient relative humidity, but in situ measurements onboard aircraft are necessarily dried. Since relative humidity can vary substantially in vertical profiles of aerosol measurements, it is important to correct the dried measurements for the swelling of hygroscopic aerosols (Ziemba et al., 2013). This is typically accomplished for aerosol scattering coefficients by obtaining tandem measurements at low and high relative humidities and then fitting empirical curves through the measurements at these two reference humidities. However, aerosol scattering increases exponentially with respect to relative humidity, so the empirical fits are not precise.

Absorption measurements that rely upon filter techniques do not fare well for aqueous-phase aerosols, so measurements of aerosol absorption on board aircraft do not generally include tandem instruments. Thus, single-scatter albedo measurements that are determined by using absorption can only be partially corrected for humidification (i.e., the scattering or extinction component is corrected, but the absorbing component is not). This is not an issue when all of the absorbing aerosols are hydrophobic (like dust and externally mixed soot carbon), but absorbing aerosols that are internally mixed with hygroscopic aerosols can pose a problem (e.g., $\mathrm{sC}$ coated with water-soluble organics).

At a minimum, any attempt to validate AERONET with aircraft profiles should include a column AOD comparison. The AERONET AODs are robust measurements based upon the extinction law, and they do not require the radiative transfer modeling that is used for the almucantar products. Since AOD is an extrinsic aerosol property and is obtained at ambient relative humidity, it enables a "check" for the aircraft profiles which improves confidence that (1) all atmospheric layers with significant aerosol mass have been adequately sam-

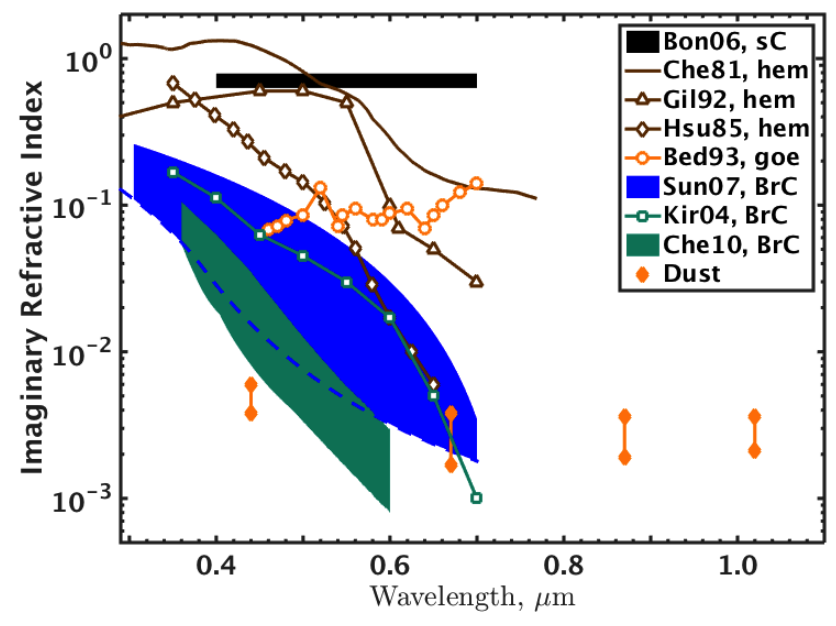

Figure 1. Imaginary refractive index of several absorbing aerosols. Bon06 is soot carbon (Bond and Bergstrom, 2006); Che81 is hematite (Chen and Cahan, 1981); Gil92 is hematite (Gillespie and Lindberg, 1992); Hsu85 is hematite (Hsu and Matijević, 1985); Bed93 is goethite (Bedidi and Cervelle, 1993); Sun07 is brown carbon (Sun et al., 2007); Kir04 is brown carbon (Kirchstetter et al., 2004); Che10 is brown carbon (Chen and Bond, 2010); Dust is the range of AERONET dust climatologies over Africa and the Middle East.

pled by the aircraft instruments and (2) the in situ aerosol humidification corrections are reasonable. Thus, data from aircraft profiles that are unable to produce the correct column AOD should be omitted from analyses attempting to validate the AERONET retrieval products.

\section{Method}

There are four absorbing aerosols species that are commonly found in the atmosphere: $\mathrm{sC}, \mathrm{BrC}$, hematite, and goethite. Soot carbon and brown carbon are produced by the same combustion sources, and they generally coexist in aerosol layers. Hematite and goethite are different forms of "free" iron, and they typically appear together as well (Arimoto et al., 2002; Lafon et al., 2006; Shi et al., 2012; Formenti et al., 2014). Our task is to separate the various contributions of these absorbing aerosol species.

Our approach utilizes imaginary refractive index, which we present for the common absorbing aerosols in Fig. 1. Note that the BrC imaginary refractive index is substantial at UV wavelengths, decreases dramatically as wavelength increases throughout the visible, and absorbs negligibly at wavelengths longer than about $0.7 \mu \mathrm{m}$ (Kirchstetter et al., 2004; Hoffer et al., 2006; Sun et al., 2007; Dinar et al., 2008; Chakrabarty et al., 2010; Chen and Bond, 2010; Lack et al., 2012).

Dust particles containing hematite also have a strong spectral signature, with the greatest absorption occurring at the UV and blue wavelengths. It is generally assumed that the hematite imaginary index is spectrally flat in the near in- 
frared region $(\sim 0.7-1 \mu \mathrm{m})$, but measurements are sparse at those wavelengths. Nonetheless, the AERONET climatologies shown in Fig. 1 corroborate a flat spectral signature at the $0.67-1.02 \mu \mathrm{m}$ wavelengths for absorbing dust, as does Dubovik et al. (2002a), Kim et al. (2011), and Wagner et al. (2012).

Since both $\mathrm{BrC}$ and hematite have strong spectral dependencies for the imaginary index, mixtures of carbonaceous aerosols and dust can not be unambiguously partitioned on the basis of the imaginary index alone. Fortunately, we can separate these particles by size, since carbonaceous particles are dominated by fine mode particles and dust is dominated by coarse mode particles; thus, our retrieval initially populates the fine mode with $\mathrm{BrC}$ and the coarse mode with dust. Unfortunately, the AERONET imaginary indices over regions like West Africa often indicate greater spectral dependencies than is observed in biomass burning aerosols (requiring $\mathrm{BrC} / \mathrm{sC}$ mass ratios greater than 15.2 in the fine mode). Likewise, the 675-1020 nm imaginary indices in the AERONET database are often greater than is observed in pure dust and would require free iron fractions greater than $10 \%$ in the coarse mode (if no other absorbers were present). We solve this difficulty by populating some of the fine mode with free iron and some of the coarse mode with carbonaceous aerosols (which is qualitatively consistent with what is found in nature).

The foundation of the retrieval is presented in Sect. 3.1, which demonstrates the range of imaginary refractive indices that we can reasonably expect to observe for dust or carbonaceous aerosols. Next, we use AERONET data to illustrate how the imaginary refractive indices of dust and carbonaceous aerosols differ (Sect. 3.2). Finally, the results of Sect. 3.1 and 3.2 are applied in Sect. 3.3 to retrieve the component volume fractions of $\mathrm{sC}, \mathrm{BrC}$, and free iron.

\subsection{Aerosol layers with two absorbing species}

If we know that we are observing "pure" dust or "pure" biomass burning aerosols, we can use the imaginary refractive indices shown in Fig. 1 to retrieve the relative fractions of hematite and goethite in the dust or $\mathrm{sC}$ and $\mathrm{BrC}$ in the biomass burning aerosols. Later, we will discuss a technique for retrieving absorbing aerosol species in more complex aerosol mixtures. The basic procedure is presented in Schuster et al. (2005), which we briefly review here.

A schematic of our approach is illustrated in Fig. 2. The operational AERONET product assumes that all particles have the same homogeneous refractive index, which implies that all particles are internally mixed (as in Fig. 2b of Bond and Bergstrom, 2006). Thus, our task is to determine an internal mixture of aerosols that produce the AERONET refractive indices at all available wavelengths. The complex refractive index of an aerosol mixture that contains a nonabsorbing host aerosol (i.e., $k_{\text {host }}=0$ ) and two absorbing inclusions can be expressed as a function $(F)$ of the volume

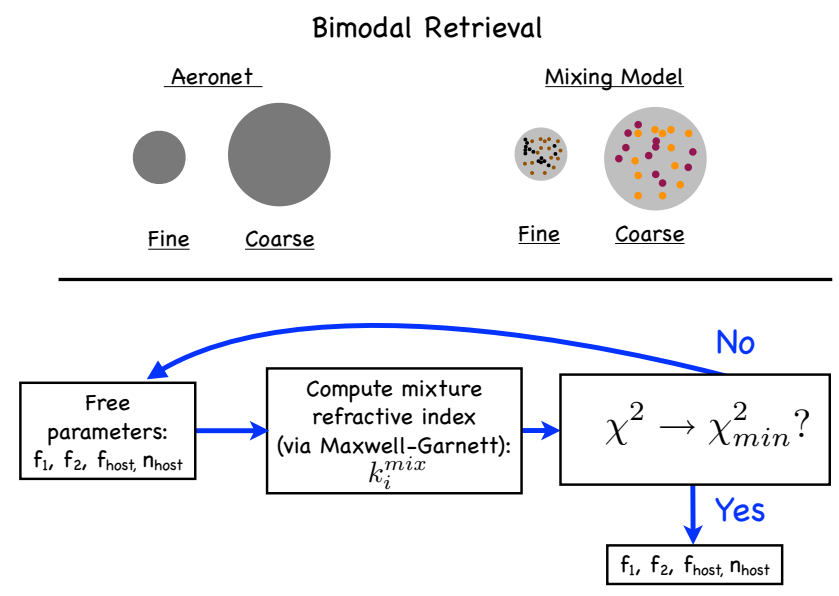

Figure 2. Schematic illustrating carbonaceous aerosol retrieval (sC and $\mathrm{BrC}$ ) for the fine mode and free iron retrieval (goethite and hematite) for the coarse mode. AERONET provides refractive indices for uniform particles, and the retrieval uses different components for each mode to find a mixture that matches the AERONET refractive indices.

fraction of the inclusions $\left(f_{i}\right)$, the complex refractive index of the inclusions $\left(m_{i}=n_{i}+i k_{i}\right)$, and the real refractive index of the host aerosol $\left(n_{\text {host }}\right)$ :

$m_{\text {mix }}\left(\lambda_{j}\right)=F\left(f_{1}, f_{2}, m_{1}\left(\lambda_{j}\right), m_{2}\left(\lambda_{j}\right), n_{\text {host }}\left(\lambda_{j}\right)\right)$,

where $\lambda_{j}$ represents wavelength of interest. In practice, Eq. (1) is implemented for each aerosol mode using the Maxwell Garnett effective medium approximation (EMA), the Bruggeman EMA, or volume averaging (Bohren and Huffman, 1983; Schuster et al., 2005). Volume averaging provides the simplest method for determining $m_{\text {mix }}$ (i.e., $\left.m_{\text {mix }}=\sum_{i} f_{i} m_{i}\right)$, but the Maxwell Garnett and Bruggeman EMAs are determined from the complex dielectric constants of the host and inclusions; therefore they require additional equations for conversion to the refractive index (see Bohren and Huffman, 1983). The Maxwell Garnett and Bruggeman EMAs differ by less than $5 \%$ (Lesins et al., 2002), so we use the Maxwell Garnett EMA because of its superior computational speed. We also note that the Maxwell Garnet EMA accurately represents the mass absorption cross section of $\mathrm{sC}$ particles with a collapsed aggregate morphology when compared to discrete dipole approximation computations; the Maxwell Garnett EMA also performs better than the coreshell model for such particles (Martins et al., 1998).

If the inclusion refractive indices $\left(m_{i}\right)$ are known, we can compute the inclusion fractions and the host refractive index that "best" matches the AERONET refractive indices $\left(m_{\mathrm{rtr}}\right)$ by iterating $f_{i}$ and $n_{\text {host }}$ until a minimum $\chi^{2}$ value is achieved (Schuster et al., 2005): 


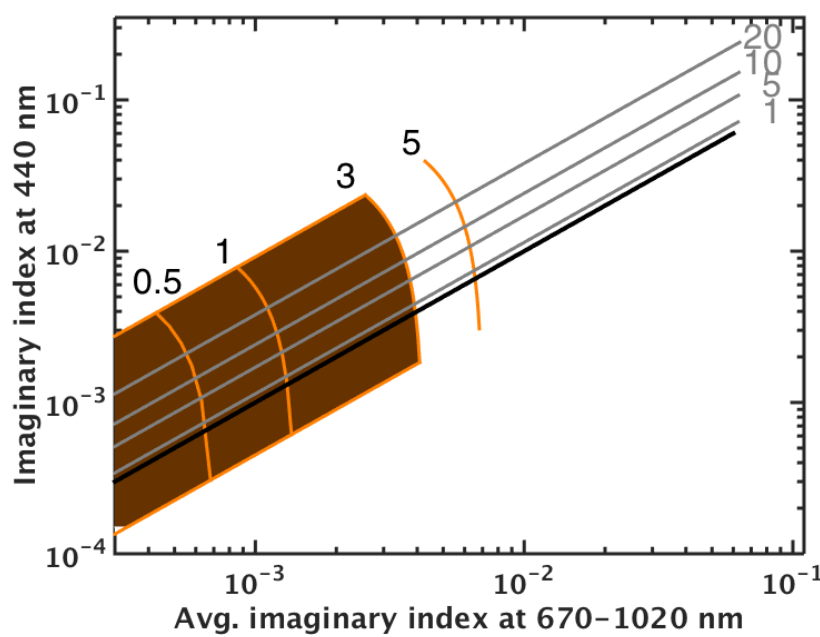

Figure 3. Theoretical imaginary refractive index space occupied by dust and carbonaceous aerosols. Shaded area indicates imaginary refractive indices at the AERONET wavelengths that are possible with mixtures of $0-3 \%$ free iron by volume in the form of hematite and/or goethite (as denoted by the labeled orange isolines). The bottom border of the shaded area represents a $0 \%$ hematite isoline, and the top border represents a $0 \%$ goethite isoline. The $x$ axis is an average for the 670,870 , and $1020 \mathrm{~nm}$ wavelengths $\left(k_{\mathrm{rnir}}\right)$. Solid black line presents spectrally invariant refractive index, as expected for soot carbon (sC). Solid grey lines indicate $\mathrm{BrC} / \mathrm{sC}$ mass mixing ratios of $1,5,10$, and 20 when no absorbing dust is present.

$$
\begin{aligned}
\chi^{2} & =\sum_{j=1}^{4} \frac{\left(n_{\mathrm{rtr}}\left(\lambda_{j}\right)-n_{\mathrm{mix}}\left(\lambda_{j}\right)\right)^{2}}{n_{\mathrm{rtr}}\left(\lambda_{j}\right)} \\
& +\frac{\left(k_{\mathrm{rtr}}\left(\lambda_{j}\right)-k_{\operatorname{mix}}\left(\lambda_{j}\right)\right)^{2}}{k_{\mathrm{rtr}}\left(\lambda_{j}\right)} \rightarrow 0 .
\end{aligned}
$$

The solution is unique because the co-emitted absorbing aerosols that we consider ( $\mathrm{sC}$ and $\mathrm{BrC}$ or hematite and goethite) have different spectral signatures, as shown in Fig. 1. Thus, the $\mathrm{sC}$ mixing ratio in the fine mode is determined by the $670-1020 \mathrm{~nm}$ wavelengths (since $\mathrm{BrC}$ exhibits little or no absorption in this spectral region). Likewise, a unique combination of hematite and goethite exists that provides the "best" match to the AERONET-retrieved refractive indices for the coarse mode.

Note that the host species is generally a mixture of components itself, with an unknown refractive index. Thus, we allow the real refractive index $n_{\text {host }}$ to be a free parameter that is retrieved (unlike in Schuster et al., 2005, where we assumed that the host was water). We assume that all absorption is caused by $\mathrm{sC}$ and $\mathrm{BrC}$ or hematite and goethite, and the host species is non-absorbing (i.e., $k_{\text {host }}(\lambda)=0$ ). We also assume that the real refractive index of the host is spectrally flat $\left(\mathrm{d} n_{\text {host }} / \mathrm{d} \lambda=0\right)$. Finally, the real refractive index of $\mathrm{BrC}$ is not well characterized, so we assume that it has the same refractive index as the host aerosol (i.e., $n_{\mathrm{BrC}}=n_{\text {host }}$ ).

\section{Imaginary refractive index space for dust and carbonaceous aerosols}

We can use the Maxwell Garnett effective medium approximation (Bohren and Huffman, 1983) to determine the theoretical range of imaginary refractive indices expected for atmospheric dust that contains only hematite and goethite as absorbing species (i.e., no carbonaceous aerosols), which we present as the shaded area in Fig. 3. In this case, $f_{1}=f_{\mathrm{h}}$ is the volume fraction of hematite and $f_{2}=f_{\mathrm{g}}$ is the volume fraction of goethite. We use a real refractive index of 1.5 for the host aerosol, Chen and Cahan (1981) for the hematite refractive indices, Bedidi and Cervelle (1993) for the goethite refractive indices (see Table 1), and assume that all other minerals present have negligible absorption throughout the UV/near-infrared range of wavelengths. (We discuss the repercussions of using different refractive indices in the Sect. 5.) Field measurements indicate that free iron mass concentrations are typically less than about $5 \%$ (Lafon et al., 2004; Wagner et al., 2012). Hematite and goethite have densities that are much higher than common clay minerals $\left(4.28-5.26 \mathrm{~g} \mathrm{~cm}^{-3}\right.$ for goethite and hematite; $2-3 \mathrm{~g} \mathrm{~cm}^{-3}$ for illite, montmorillonite, and kaolinite), so this corresponds to a maximum of about $3 \%$ free iron by volume. Thus, we present the range of computed refractive indices associated with up to $3 \%$ free iron (by volume) as the shaded area in Fig. 3. The bottom border of the shaded area represents an $f_{\mathrm{h}}=0$ isoline and the top border represents an $f_{\mathrm{g}}=0$ isoline. Finally, the numbers along the top of the shaded area indicate the total percentage of free iron (i.e., hematite plus goethite) on the vertical isolines (we also include an additional isoline outside of the shaded area for $5 \%$ free iron).

In order to complete our description of two co-emitted aerosol absorbers in $k(440)$ vs. $k_{\text {rnir }}$ space, we similarly compute refractive indices for mixtures of carbonaceous aerosols. In this case, $\mathrm{sC}$ and $\mathrm{BrC}$ are the only absorbing species and $f_{1}=f_{\mathrm{sC}}, f_{2}=f_{\mathrm{BrC}}$. We use a spectrally invariant imaginary index of $m_{\mathrm{SC}}=1.95+0.79 i$ for soot carbon (Bond and Bergstrom, 2006) and the Kirchstetter et al. (2004) measurements for BrC (see Fig. 1). The solid black line in Fig. 3 is a $1: 1$ line, and it represents the spectrally invariant refractive index of soot carbon. The grey lines above the black line in Fig. 3 denote the contribution of brown carbon, with $\mathrm{BrC} / \mathrm{sC}$ mass mixing ratios ranging from 1 to 20 (assuming that $\mathrm{sC}$ has a density of $1.8 \mathrm{~g} \mathrm{~cm}^{-3}$ and $\mathrm{BrC}$ has a density of $1.2 \mathrm{~g} \mathrm{~cm}^{-3}$, as in Bond and Bergstrom, 2006; Turpin and Lim, 2001).

\subsection{Separation of dust and carbonaceous aerosols}

The previous section provides a theoretical range of values expected for both dust and carbonaceous aerosols in the imaginary refractive index space of Fig. 3. Note that there is substantial overlap of the imaginary refractive indices computed for dust (shaded area) and carbonaceous aerosols (grey 
Table 1. Refractive indices used to test sensitivity of this retrieval to component aerosol optical properties. The subscript "rnir" refers to the red and near infrared wavelengths, and $k_{\text {rnir }}$ is the average $k$ for the $670-1020 \mathrm{~nm}$ wavelengths.

\begin{tabular}{llllll}
\hline Species & $k(440)$ & $k\left(\lambda_{\text {rnir }}\right)$ & $\frac{k(440)}{k\left(\lambda_{\text {rnir }}\right)}$ & $\lambda_{\text {rnir }}(\mu \mathrm{m})$ & Reference \\
\hline This retrieval & & & & & \\
\hline Soot carbon & 0.790 & 0.790 & 1.0 & $0.670-1.020$ & Bond and Bergstrom (2006) \\
Brown carbon & 0.063 & 0.001 & 63.0 & 0.700 & Kirchstetter et al. (2004) \\
Hematite & 1.229 & 0.127 & 9.7 & $0.670-0.700$ & Chen and Cahan (1981) \\
Goethite & 0.068 & 0.120 & 0.6 & $0.660-0.700$ & Bedidi and Cervelle (1993) \\
\hline Other measurements & & & & \\
\hline Soot carbon & 0.630 & 0.630 & 1.0 & $0.670-1.020$ & Bond and Bergstrom (2006), low extreme \\
Brown carbon & 0.127 & 0.006 & 21.2 & $0.670-0.700$ & Sun et al. (2007), WSOC \\
Brown carbon & 0.016 & 0.002 & 8.0 & $0.670-0.700$ & Sun et al. (2007), WIOC \\
Brown carbon & 0.035 & 0.001 & 35.0 & 0.600 & Chen and Bond (2010) \\
Hematite & 0.27 & 0.006 & 45.0 & 0.650 & Kerker et al. (1979) ${ }^{\mathrm{c}}$ \\
Hematite & 0.59 & 0.040 & 14.8 & 0.675 & Gillespie and Lindberg (1992) \\
\hline
\end{tabular}

${ }^{a}$ water soluble organic carbon; ${ }^{b}$ water insoluble organic carbon. ${ }^{c}$ As tabulated by Hsu and Matijević (1985).

Table 2. AERONET sites used in this study.

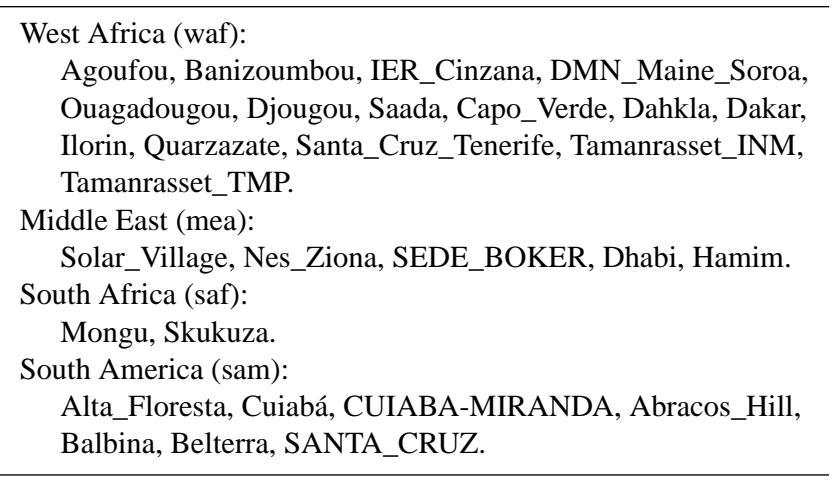

and black isolines) in Fig. 3. Thus, additional constraints are needed to separate dust from carbonaceous aerosols, which we discuss in this section.

We begin by assessing "pure" dust over the Middle Eastern sites listed in Table 2, and plot AERONET Level 2 retrievals in Fig. 4a. We define "pure" dust as retrievals with fine mode volume fractions (fvf) less than or equal to 0.05 and lidar depolarization ratios $(\delta p)$ greater than or equal to 0.2 at the $0.532 \mu \mathrm{m}$ wavelength (Schuster et al., 2012). Note that all of the retrievals in Fig. 4a lie in the shaded region, indicating that these AERONET retrievals are consistent with the free iron fractions found in the literature and the refractive indices that we used to compute the shaded region.

Similarly, we plot the AERONET retrievals from the South American sites during the peak of the biomass burning season in Fig. 4b. Note that these aerosols tend to have much higher imaginary indices at the red and near-infrared wavelengths $\left(k_{\text {rnir }}\right)$ than the dust aerosols of Fig. $4 \mathrm{a}$, and most of the retrievals do not occupy the shaded area. This is because biomass burning aerosols are generally more absorbing than dust at $0.670-1.020 \mu \mathrm{m}$. Also note that our retrieved $\mathrm{BrC} / \mathrm{sC}$ mass ratio for biomass burning aerosols is always less than 15.2, which is an important constraint for retrieving mixtures of dust with carbonaceous aerosols (described in Sect. 3.3).

There is a clear separation between the dust and biomass burning aerosols in Fig. 4 - the carbonaceous aerosols are much more absorbing at the red and near-infrared wavelengths than the dust aerosols. Thus, we explore this phenomenon as a means of separating dust from carbonaceous aerosols using the box plots of Fig. 5. The biomass burning sites in Fig. 5 are considered only during the peak of the biomass burning seasons in order to minimize possible contamination by dust (August-September for South America, July-September for South Africa). We have used two different techniques to minimize carbonaceous aerosol contamination of dust. The middle pair of boxes in Fig. 5 are restricted to retrievals with fine volume fraction less than 0.05 and lidar depolarization ratios greater than 0.2 at the $0.532 \mu \mathrm{m}$ wavelength (as in Fig. 4a and Schuster et al., 2012). Some readers may desire a stricter constraint, so we also limit the retrievals to $\mathrm{AE} \leq 0$ for the first pair of boxes in Fig. 5. This is a stringent requirement that demands high coarse mode concentrations and allows very little pollution or biomass burning in the data set (Ginoux et al., 2012); unfortunately, this restriction reduces the size of our data set to $\sim 100$ points (see the right axis of Fig. 5). Both restrictions for dust result in similar medians, but the Schuster et al. (2012) restriction has larger upper limits than the $\mathrm{AE} \leq 0$ restriction (compare the leftmost pair of box plots to the middle pair of box plots). Neither technique results in any overlap of the whiskers at the dust regions with the whiskers at the biomass burning regions in Fig. 5. 


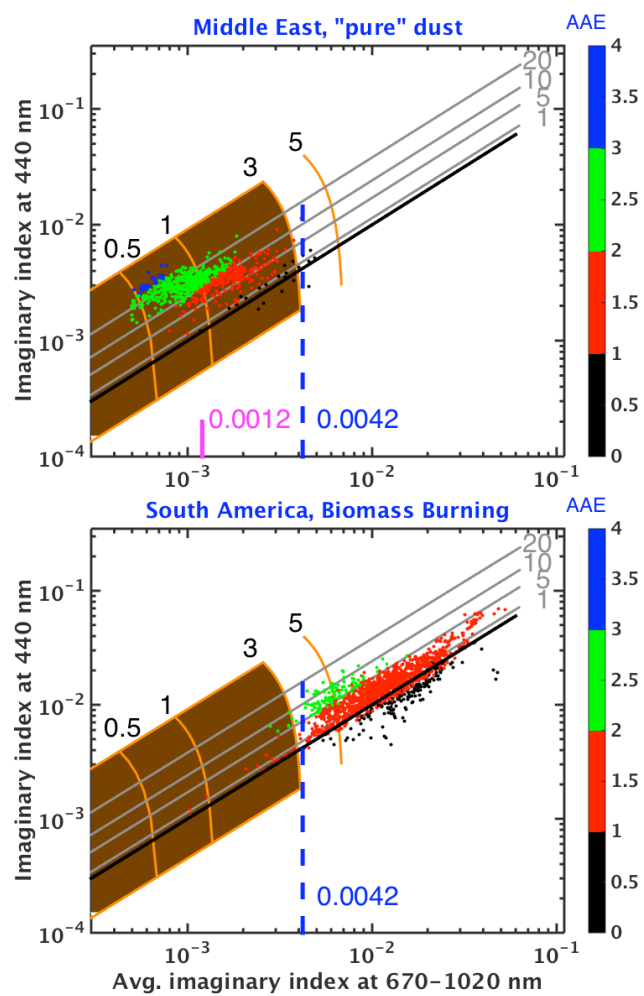

Figure 4. AERONET Level 2.0 imaginary refractive indices (color code corresponds to the absorption Ångström exponent). Top panel: data over the Middle East, filtered to retain only dust (i.e., require fine volume fractions less than 0.05 and depolarizations greater than 0.2 at the $532 \mathrm{~nm}$ wavelength). Vertical magenta line denotes the median. Bottom panel: South American biomass burning sites for August and September. The vertical dashed line at $k_{\text {rnir }}=0.0042$ separates $95 \%$ of the two data sets. See Table 2 for a listing of AERONET sites used in these regions.

Thus, there is less than $5 \%$ overlap between any of the dust distributions with either of the biomass burning distributions, and the horizontal dashed line at $k_{\text {rnir }}=0.0042$ separates at least $95 \%$ of the dust and biomass burning aerosols. Finally, we note that $k_{\text {rnir }}=0.0042$ corresponds to a volumeaveraged free iron content of about $3.4 \%$ when using the Chen and Cahan (1981) refractive indices for hematite and the Bedidi and Cervelle (1993) refractive indices for goethite; this can also be inferred by the close proximity of the $k_{\text {rnir }}=$ 0.0042 line to the $3 \%$ free iron isoline in Fig. 4 . Note that $3.4 \%$ free iron by volume is roughly equivalent to $6.8 \%$ free iron by mass, since the density of free iron is roughly twice that of other minerals (Formenti et al., 2014). Thus, this is consistent with the maximum $6.5 \%$ free iron content measured by Lafon et al. (2006).

\subsection{Aerosol layers with up to four absorbing species}

We outlined the imaginary refractive index space occupied by dust and carbonaceous aerosols in Sect. 3.1. The absorp-

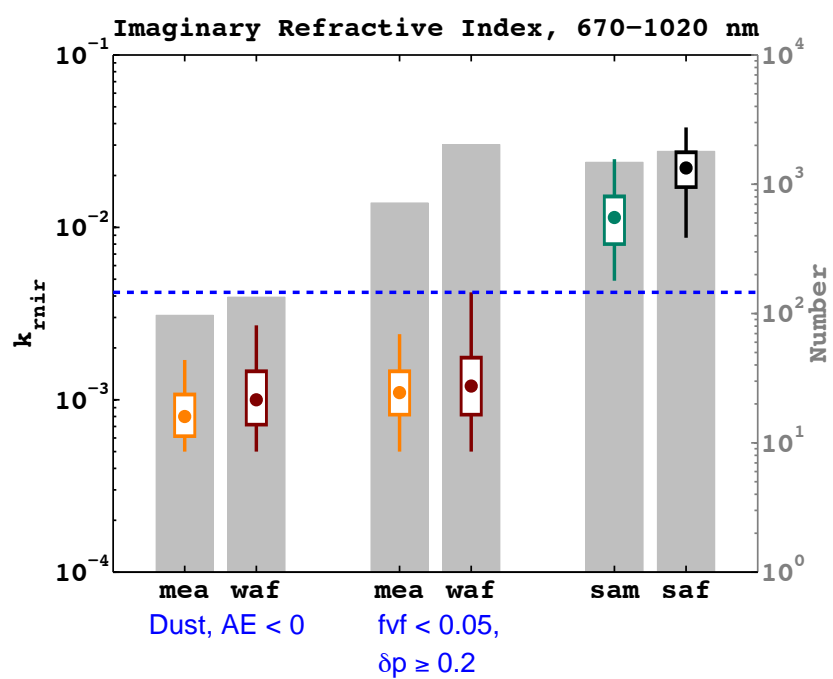

Figure 5. Box plots for the Level 2.0 imaginary refractive indices averaged over the $670-1020 \mathrm{~nm}$ wavelengths at the AERONET sites listed in Table 2. Circles represent medians; box edges are the 25th and 75th percentiles; whisker ends are the 5th and 95th percentiles. Grey bars indicate the number of data points contributing to each box plot. The Middle Eastern (mea) and West African (waf) sites are filtered for dust using two different methods. Biomass burning sites are considered only during the peak of the biomass burning seasons (August-September for South America, or sam; July-September for South Africa, or saf). The dashed blue line illustrates that $k_{\text {rnir }}=$ 0.0042 separates at least $95 \%$ of the dust and biomass imaginary refractive indices.

tion for both of these aerosol types can be described with two absorbing aerosol species (hematite and goethite for dust, organic and black carbon for carbonaceous aerosols). However, mixtures of dust with biomass burning require us to include four absorbers in the retrieval, which we discuss in this section.

Our basic approach is outlined in Fig. 6. Since carbonaceous aerosols are mainly found in the fine mode (radii $\lesssim 0.6 \mu \mathrm{m}$ ), we initially assume that all $\mathrm{sC}$ and $\mathrm{BrC}$ are located in that mode. Likewise, free iron is mainly internally mixed with other minerals, and are the dominant absorbers in coarse mode dust (Sokolik and Toon, 1999; Lafon et al., 2006; Kandler et al., 2009; Wagner et al., 2012), so we initially assume that all hematite and goethite are located in the coarse mode. Unfortunately, we can not maintain all carbon in the fine mode and all free iron in the coarse mode for all aerosol retrievals; this is because AERONET provides a single refractive index for particles in both the fine and coarse modes, and sometimes the retrieved refractive indices can not be achieved with reasonable concentrations of a twoabsorber mixture.

This conundrum is illustrated in Fig. 7, where we present all level 2.0 AERONET retrievals at the West African sites in $k_{440}$ vs. $k_{\text {rnir }}$ space. Aerosols at these sites include substantial concentrations of dust throughout the year, as well 


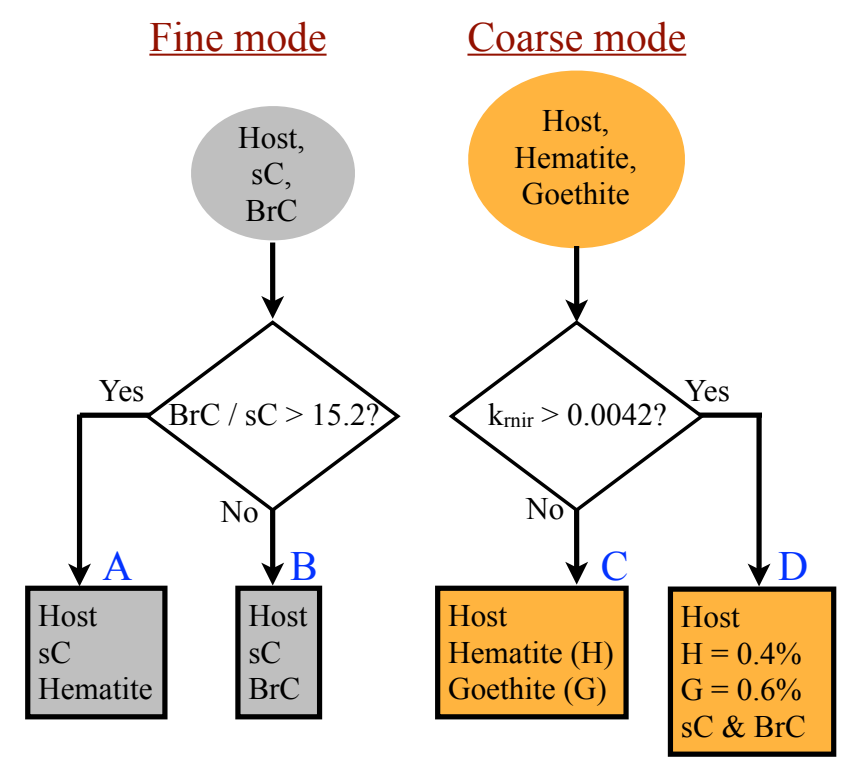

Figure 6. Flowchart showing absorbing aerosol retrieval process. Initially, all carbonaceous species are assumed to occupy the fine mode and all iron oxide (hematite, goethite) is assumed to occupy the coarse mode. If $\mathrm{BrC} / \mathrm{sC}>15.2$ would be required for a twocomponent mixture, then hematite is used instead of $\mathrm{BrC}$ to characterize the spectral dependence of the refractive index in the fine mode (branch A). Likewise, if the retrieved absorption at the red and near-infrared wavelengths is above a threshold of $k_{\text {rnir }}=0.0042$, then the hematite and goethite fractions are fixed at the values we retrieved for "pure" African dust, and some carbonaceous aerosol is assumed to occupy the coarse mode (branch D).

as seasonal biomass burning (Derimian et al., 2008). The points above the uppermost grey line in Fig. 7 would require $\mathrm{BrC} / \mathrm{sC}$ mass ratios higher than 20 for the fine mode with our scheme (if we did not make an adjustment). However, the $\mathrm{BrC} / \mathrm{sC}$ ratio is never greater than 15.2 for the South American biomass burning aerosols in Fig. $4 \mathrm{~b}$ (this is also true for the South African biomass burning sites of Table 2). Hence, the retrievals with $\mathrm{BrC} / \mathrm{sC}>20$ in Fig. 7 are actually dominated by dust, so including extreme values of $\mathrm{BrC}$ in the fine mode to obtain the correct spectral dependence for the imaginary index is not realistic.

Thus, we use hematite instead of $\mathrm{BrC}$ to represent the spectral dependence of the fine mode when the $\mathrm{BrC} / \mathrm{sC}$ ratio exceeds 15.2; this is diagrammed in the left flowchart of Fig. 6 . This is qualitatively consistent with observations, as iron-rich dust is known to exist in the fine mode as well as the coarse mode when such dust is present (Kandler et al., 2007; Derimian et al., 2008). This branch of the code is necessary for $12 \%$ of the retrievals in West Africa and $14 \%$ of the retrievals in the Middle East, but it is never called for the retrievals in South America or southern Africa.

Likewise, AERONET retrievals with refractive indices to the right of the shaded area in Fig. 7 likely contain biomass burning aerosols (as in Fig. 4b). Attempting to model the

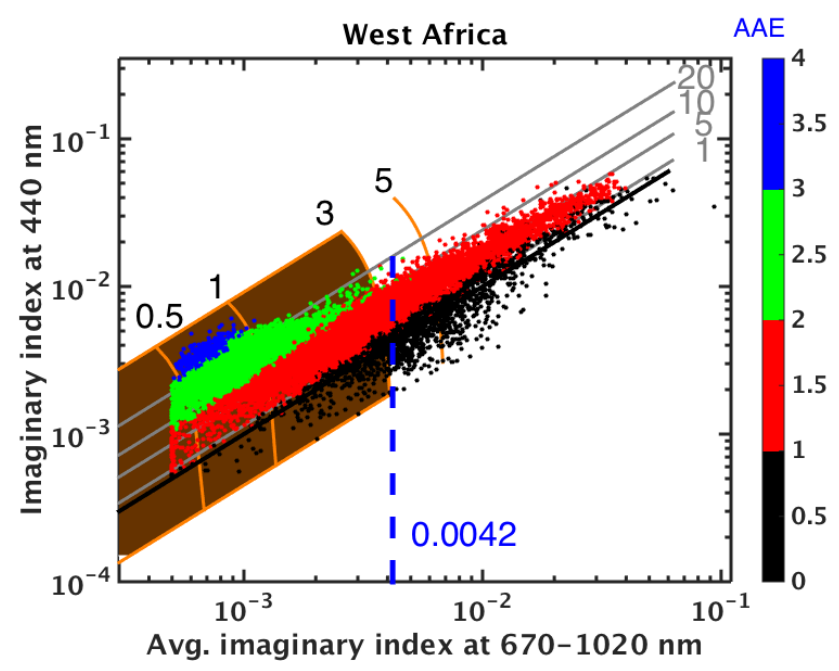

Figure 7. All level 2.0 retrievals for the West African AERONET sites of Table 2, including mixtures of biomass burning and dust. Many of the points are located above the uppermost grey line, which would require $\mathrm{BrC} / \mathrm{sC}$ ratios greater than 15.2 for a mixture containing only carbonaceous aerosols. Likewise, retrievals to the right of the shaded area require iron oxide volume mixing ratios greater than $3 \%$ if no carbonaceous aerosol is included.

coarse mode without carbonaceous aerosols will require free iron concentrations exceeding 5 or even $10 \%$ by volume for that mode (since these data fall to the right of the $5 \%$ free iron oxide isolines in Fig. 7). This is unrealistic, so we separate carbonaceous and free iron aerosol absorption at $k_{\text {rnir }}=0.0042$, as inferred from the box plots of Fig. 5. That is, we fix the free iron volume concentration at $1 \%$ for the coarse mode when $k_{\text {rnir }}>0.0042$ (based upon the retrieved median for pure dust at the West African and Middle Eastern sites), as diagrammed in the right flowchart of Fig. 6. Then the remainder of the absorption for that mode is accounted for with $\mathrm{sC}$ and $\mathrm{BrC}$. This branch of the code is necessary for $24 \%$ of the retrievals in West Africa, $17 \%$ of the retrievals in the Middle East, and $96-98 \%$ of the retrievals at the biomass burning sites in South America and southern Africa. Although carbonaceous aerosols are sometimes observed attached to coarse mode dust (Derimian et al., 2008; Hand et al., 2010), it is also likely that the AERONET product redistributes some fine mode absorption to the coarse mode (Schuster et al., 2016).

Our choice of $1 \%$ free iron in branch D of Fig. 6 is based upon climatology for pure dust at the West African and Middle Eastern sites. We retrieve median hematite and goethite fractions of 0.39 and $0.62 \%$ for pure dust in West Africa, and 0.34 and $0.58 \%$ for pure dust in the Middle East, 0.38 and $0.62 \%$ when both these regions are combined. This corresponds to $k_{440 / 674 / 870 / 1020=}$ $0.0036 / 0.0014 / 0.0013 / 0.0013$ for pure dust in the combined data set, which is also consistent with Kim et al. (2011). 

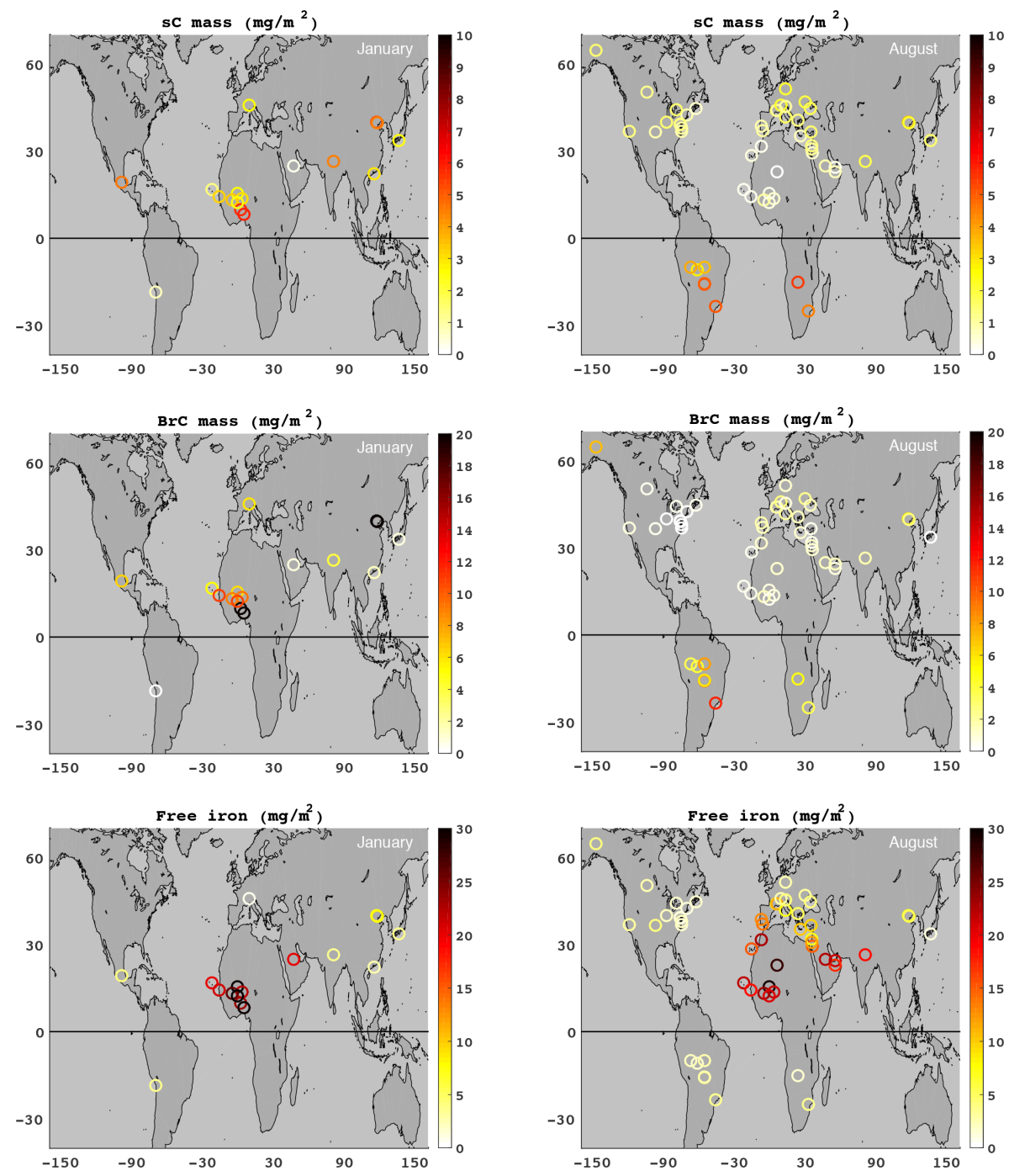

Figure 8. Column mass concentrations of sC (top row), $\mathrm{BrC}$ (middle row), and iron oxide (bottom row) retrieved from Level 2.0 AERONET data for January (left column) and August (right column). Minimum number of retrievals is 25 for each site.

\section{Results}

We present climatological maps of the retrieved column mass of $\mathrm{sC}, \mathrm{BrC}$, and free iron in Fig. 8. We begin our discussion with the right column of Fig. 8, which presents our retrieved concentrations for the month of August. This is near the peak of the biomass burning season at the southern hemispheric sites, and the retrieval indicates higher $\mathrm{sC}$ concentrations in those regions than in the rest of the world. The retrieval also indicates elevated concentrations of $\mathrm{BrC}$ in those regions (right middle panel), consistent with our expectations for biomass burning regions. Likewise, the urban regions of North America, Europe, and Asia indicate intermediate concentrations of sC and little BrC. Finally, we note that the West African sites indicate little or no carbonaceous aerosols during the month of August, consistent with the lack of biomass burning in that region at that time. Note the elevated iron concentrations in West Africa, however, as well as the high concentrations of iron in the Middle East, India, and parts of Europe (bottom right panel).

The month of January tells a different story (left column of maps in Fig. 8). The West African sites have high concentrations of $\mathrm{sC}$ and $\mathrm{BrC}$ during this month, reflecting the strong winter biomass burning signal that occurs there. The dust signal also remains at those sites, however, as indicated by the large iron concentrations shown in the lower left map. Note that the Saudi Solar Village site on the Arabian Peninsula also indicates high iron concentrations in both January and August, but the carbonaceous aerosol signal does not exist there in either month. Taken together, maps of these two regions (West Africa and the Middle East) indicate that the retrieval is able to discriminate dust aerosols from mixtures of dust and carbonaceous aerosols. 

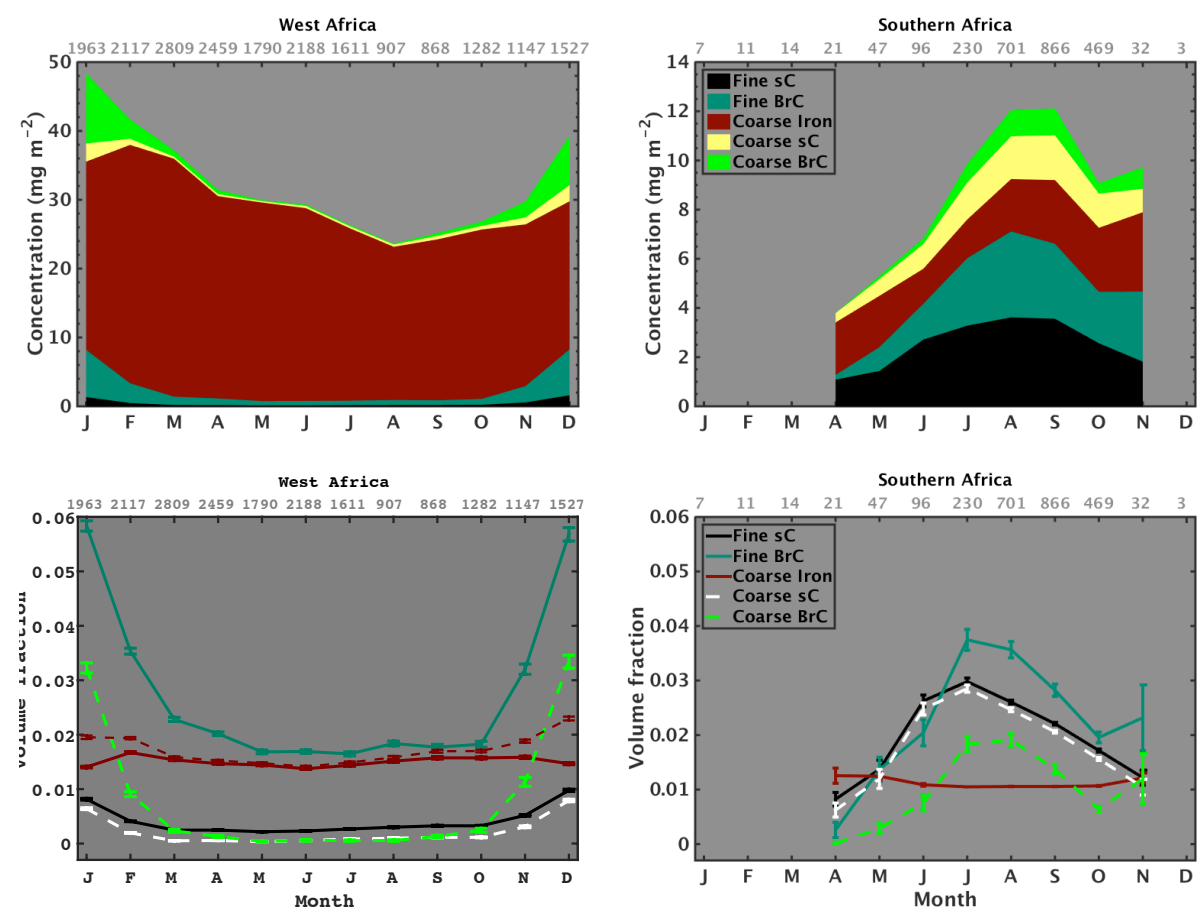

Figure 9. Upper panels: monthly averaged column concentrations of retrieved sC, $\mathrm{BrC}$, and free iron in the fine and coarse modes at the West African and southern African sites (fine mode iron is negligible at these scales). Note the difference in $y$ axis scales. Lower panels: monthly averaged volume fractions at the same sites. Extra dashed maroon line for West Africa indicates monthly averages for coarse mode iron, but computed without using retrievals that require branch D of Fig. 6. Error bars represent the SD of the means. Number of retrievals per month shown along upper axes; only months with more than 20 retrievals are shown in plots.

The monthly averaged absorbing aerosol concentrations for the two African regions are shown in the upper panels of Fig. 9, broken down by species for each mode (see Table 2 for locations). Here, we see that the West African dust sites are dominated by free iron, whereas the biomass burning sites of southern Africa are dominated by carbonaceous aerosols. We also present the seasonal climatology of the component mixing ratios for these sites in the lower panels of Fig. 9. We show volume fractions this time (instead of column concentrations) to illustrate the intrinsic properties of the retrieval. Note that even though both African regions exhibit similar mixing ratios of free iron throughout the year (as shown in the lower panels of Fig. 9), the West African region has much higher free iron concentrations than the southern African region (as shown in the upper panels of Fig. 9). This is because the West African sites have a much stronger coarse mode than the southern African sites.

The lower left panel of Fig. 9 indicates that the volume fraction of free iron remains relatively constant in West Africa throughout the year (1.4-1.7\%, as shown by the solid maroon line). However, the signal is somewhat stabilized because we use climatological mixing ratios for iron whenever the retrieval is contaminated by carbonaceous aerosols, which constitutes $24 \%$ of the retrievals in West Africa (i.e., "branch D" of Fig. 6). Hence, we also show the monthly
Table 3. Maximum monthly climatological averages for absorbing components of the fine (f) or coarse (c) mode, in percent by volume. The AERONET sites are listed in Table 2 and the regions correspond to West Africa (WAF), Middle East (MEA), southern Africa (SAF), and South America (SAM).

\begin{tabular}{lccccc}
\hline & Mode & WAF & MEA & SAF & SAM \\
\hline Soot carbon & $\mathrm{f}$ & 1.0 & 0.4 & 3.0 & 1.7 \\
Brown carbon & $\mathrm{f}$ & 5.8 & 2.1 & 3.7 & 5.7 \\
Iron & $\mathrm{c}$ & 1.7 & 1.6 & 1.3 & 1.3 \\
\hline
\end{tabular}

averages that are obtained by omitting the contaminated retrievals (dashed maroon line in the lower left panel). Note that both monthly averages produce nearly identical free iron mixing ratios in the absence of biomass burning aerosols during the summer months. Monthly averaged free iron mixing ratios obtained during the winter biomass burning season increase when we omit retrievals that require branch $\mathrm{D}$ of Fig. 6, though, peaking at $2.3 \%$ in December. This is because omitting retrievals that require branch $\mathrm{D}$ results in a heavier weighting of the retrievals with $k_{\text {rnir }}$ greater than the median value of pure dust (i.e., $k_{\text {rnir }} \gtrsim 0.0013$ and $k_{\text {rnir }}<0.0042$ ). Thus, omitting the branch D retrievals causes the monthly iron volume fractions to increase during the biomass burn- 
ing season and more closely mimic the monthly carbonaceous aerosol signals. Hence, it is likely that some of the remaining retrievals are still contaminated with carbonaceous aerosols during the biomass burning season. Finally, we note that branch D is called for $98 \%$ of the retrievals in southern Africa, so the solid maroon line in the lower right panel indicates very little seasonality because it is dominated by climatology.

The carbonaceous signals of Fig. 9 show a very strong seasonal variability, with $\mathrm{sC}$ and $\mathrm{BrC}$ peaking at 1.0 and $5.8 \%$ for the fine mode during the West African biomass burning season. We see a similar pattern in southern Africa, with fine mode peaks of $3.0 \%$ for $\mathrm{sC}$ and $3.7 \%$ for $\mathrm{BrC}$. The peak climatological volume mixing ratios for all four regions of Table 2 are listed in Table 3.

One can discern that $\overline{\mathrm{BrC}} / \overline{\mathrm{sC}}$ volume ratio is always less than 2 at the South African sites of Fig. 9, and it is sometimes less than 1 ; indeed, the median $\mathrm{BrC} / \mathrm{sC}$ mass ratio is 0.7 during the peak of the biomass burning season. This is much lower than the organic/soot carbon mass ratios measured using in situ techniques, which typically range from 3 to 12 or more (e.g., Reid et al., 2005b; Chen and Bond, 2010). However, in situ measurements are typically reported for measurements obtained close to sources and during fire events, but monthly averages represent periods between burns as well as the burn events; this could lower the $\mathrm{BrC} / \mathrm{sC}$ ratios.

Additionally, in situ measurements typically account for all OC, whereas our retrieval is responsive only to organic species that have significant absorption at $0.440 \mu \mathrm{m}$. That is, $\mathrm{BrC}$ is part of OC (Moosmüller et al., 2009), so $\mathrm{BrC}$ concentrations are always less than $\mathrm{OC}$ concentrations, and $\mathrm{BrC} / \mathrm{sC}<\mathrm{OC} / \mathrm{sC}$. Alternatively, a greater proportion of $\mathrm{OC}$ could be encompassed by using a lower imaginary refractive index for $\mathrm{BrC}$; for instance, the median retrieved $\mathrm{BrC} / \mathrm{sC}$ volume ratio increases from 1.5 to 2.7 for the South American biomass burning season when Chen and Bond (2010) is used for the $\mathrm{BrC}$ refractive index instead of Kirchstetter et al. (2004). However, the maximum $\mathrm{BrC} / \mathrm{sC}$ value also increases from 15.2 to 27.5 , and the latter value is outside of the range outlined by Reid et al. (2005a) or Chen and Bond (2010).

Recently, some authors have attempted to use AAE to speciate carbonaceous aerosols and dust (Chung et al., 2012; Bahadur et al., 2012), so we present AAE vs. fvf for the West African and South American sites in Fig. 10. The color code in each of the panels represents the volume fraction of one of the absorbing aerosol species with respect to the total volume of all absorbing aerosol species. The fraction of $\mathrm{sC}$ is presented in the top panel, $\mathrm{BrC}$ in the middle panel, and free iron in the lower panel. Data on the left side of the panels correspond to low fvf, and therefore they are dominated by dust at the West African sites. Data on the right are dominated by biomass burning at the South American sites.

It is immediately obvious that the AAE parameter is sensitive to the relative proportions of $\mathrm{sC}$ and $\mathrm{BrC}$ when carbonaceous aerosols dominate the retrievals, as shown by the
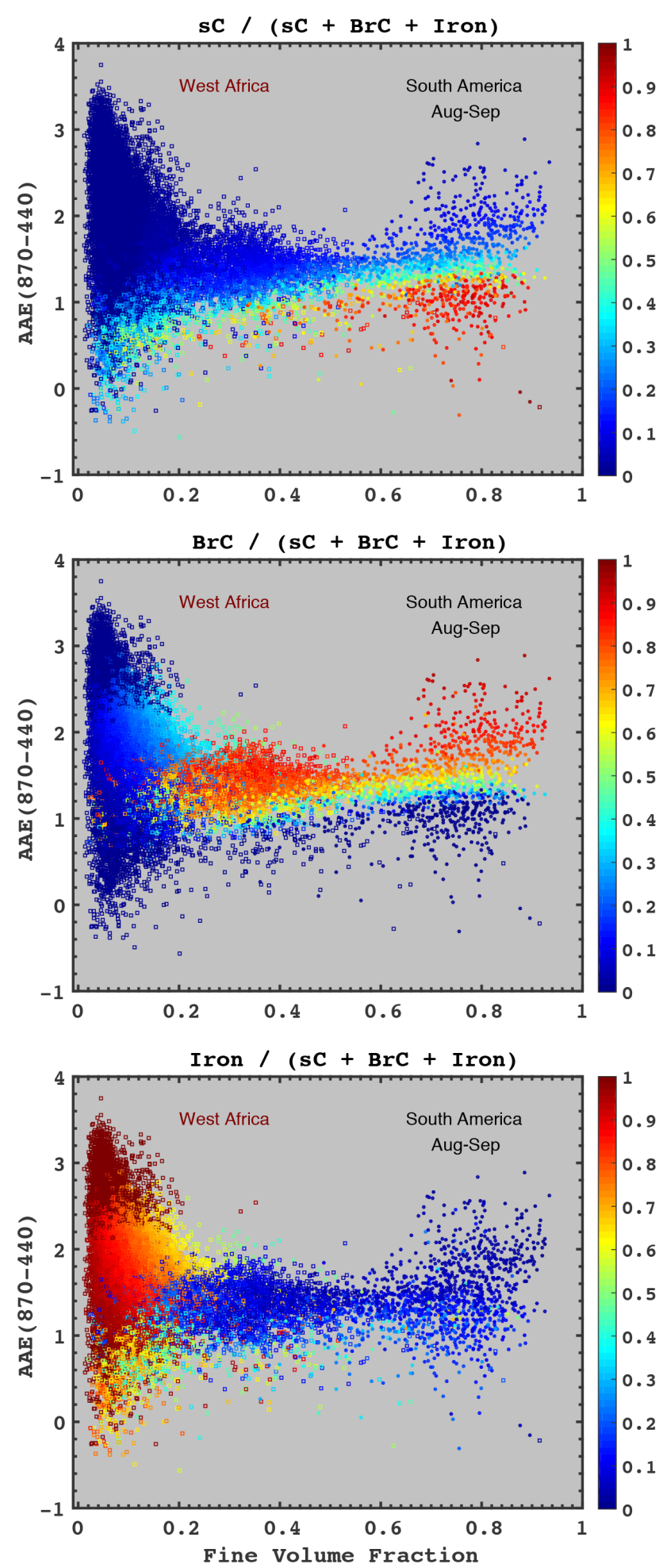

Figure 10. Volume fraction of absorbing species associated with each absorber, as a function of AAE and fine volume fraction. Data located mainly on the left are from the West African sites; data on the right correspond to the biomass burning season at the South American sites. 
Table 4. Maximum and median $\mathrm{BrC}$ volume fractions, and $\mathrm{BrC} / \mathrm{sC}$ mass ratios retrieved for fine mode aerosols at the biomass burning sites during the peak of the burning seasons (August-September for South America, July-September for southern Africa), using different $\mathrm{BrC}$ refractive indices. The refractive index used for $\mathrm{sC}$ is $m_{\mathrm{SC}}=1.95+0.79 i$.

\begin{tabular}{|c|c|c|c|c|}
\hline & \multicolumn{2}{|c|}{ Maximums } & \multicolumn{2}{|c|}{ Medians } \\
\hline & $f_{\mathrm{BrC}}$ & $\frac{\mathrm{BrC}}{\mathrm{sC}}$ & $f_{\mathrm{BrC}}$ & $\frac{\mathrm{BrC}}{\mathrm{sC}}$ \\
\hline \multicolumn{5}{|l|}{ South America } \\
\hline Sun et al. (2007) ${ }^{a}$ & 0.183 & 8.0 & 0.014 & 0.8 \\
\hline Kirchstetter et al. (2004) & 0.343 & 15.2 & 0.028 & 1.5 \\
\hline Chen and Bond (2010) ${ }^{a}$ & 0.658 & 27.5 & 0.051 & 2.7 \\
\hline Sun et al. (2007) ${ }^{b}$ & 1.000 & 47.7 & 0.116 & 6.5 \\
\hline \multicolumn{5}{|l|}{ Southern Africa } \\
\hline Sun et al. $(2007)^{a}$ & 0.111 & 5.8 & 0.012 & 0.4 \\
\hline Kirchstetter et al. (2004) & 0.230 & 11.8 & 0.023 & 0.7 \\
\hline Chen and Bond (2010) ${ }^{a}$ & 0.414 & 21.2 & 0.043 & 1.3 \\
\hline Sun et al. (2007) ${ }^{b}$ & 0.842 & 45.2 & 0.105 & 3.2 \\
\hline
\end{tabular}

${ }^{\mathrm{a}}$ Upper limit; ${ }^{\mathrm{b}}$ lower limit.

strong color gradients on the right side of the upper two panels. This is because of the strong spectral dependence of $k_{\mathrm{BrC}}$ and the wavelength-independent refractive index of $\mathrm{sC}$ shown in Fig. 1. The strong spectral dependence of $k_{\mathrm{BrC}}$ enhances the absorption at the shortest wavelengths, which increases AAE. Soot carbon has a wavelength-independent refractive index (Bond and Bergstrom, 2006; Bond et al., 2013), so the AAE of pure $\mathrm{SC}$ is smaller than the AAE of pure $\mathrm{BrC}$ for particles of the same size. Thus, both the AAE and our retrieved $\mathrm{BrC}$ are sensitive to the spectral dependence of the retrieved imaginary index, and the color gradient for carbonaceous aerosols in Fig. 10 reflects this.

However, Fig. 10 also indicates that AAE is not useful for discriminating between dust and carbonaceous aerosols. For instance, a retrieved AAE $\sim 1.2$ can not discriminate between the dust aerosols with fvf $<0.1$ on the left side of Fig. 10 and the carbonaceous aerosols with fvf $>0.7$ on the right side of Fig. 10. This is because the AAE of pure dust has a large range of possible values (from less than 0 to greater than 3), depending upon the relative fractions of hematite and goethite. Thus, the AAE of dust is not well separated from the AAE of carbonaceous aerosols along the vertical axis in Fig. 10. This is discussed further in Schuster et al. (2016).

\section{Sensitivity to component refractive indices}

The refractive indices that we use for this retrieval are outlined in the upper portion of Table 1; refractive index uncertainty in any one of these components has an affect on all of the absorbing components to some extent, which we assess in this section. We assess this uncertainty by repeatedly retrieving $\mathrm{sC}, \mathrm{BrC}$, and hematite climatologies using all of the refractive index sources listed in Table 1, and then we compare the results to our baseline retrieval. In order to stress the algorithm, we seek locations with significant concentrations of both dust and carbonaceous aerosols; thus, we use the month of January at the West African sites of Table 2. Dust is always present at those sites, and January is near the peak of the biomass burning season at those locations. We explain our baseline refractive index choices in Sect. 5.1; the sensitivity studies for $\mathrm{sC}, \mathrm{BrC}$, and free iron are presented in Sect. 5.2 and 5.3.

\subsection{Rationale for our choice of baseline refractive indices}

Bond and Bergstrom (2006) did an extensive review of sC refractive indices; they concluded that the available data were consistent with a constant refractive index at visible wavelengths. They also hypothesized that "strongly absorbing carbon with a single refractive index exists, and that some of the variation in reported refractive indices results from void fractions in the material." They recommended using $k=0.63$ 0.79 for $\mathrm{sC}$ at visible wavelengths, favoring the larger extreme for highly graphitized carbon. The spectrally invariant value of $k_{\mathrm{SC}}=0.79$ was later adopted in Bond et al. (2013). Thus, we use $m_{\mathrm{SC}}=1.95+0.79 i$ at all wavelengths as our baseline complex refractive index for $\mathrm{sC}$.

Reported values for the imaginary index of $\mathrm{BrC}$ varies by more than an order of magnitude at $\lambda=0.440 \mu \mathrm{m}$, as shown in Fig. 1 and Table 1. This is because $\mathrm{BrC}$ is a generic term for many absorbing organic carbon particles, and it does not represent a single aerosol species per se. The refractive index of $\mathrm{BrC}$ depends upon combustion conditions and the fuel source, and it therefore can vary substantially between the various AERONET sites. We require that our $\mathrm{BrC}$ retrieval produces reasonable $\mathrm{BrC}$ fractions and $\mathrm{BrC} / \mathrm{sC}$ ratios for all cases. So, for instance, Table 4 indicates that using the lower limit of Sun et al. (2007) can result in $f_{\mathrm{BrC}}$ as high as 1.0 (i.e., $100 \%$ brown carbon), which is clearly not acceptable. Fortunately, the refractive index of all $\mathrm{BrC}$ is negligible at the $670-1020 \mathrm{~nm}$ wavelengths (see Fig. 1), so BrC refractive index does not have a substantial impact on the retrieved $\mathrm{sC}$ mixing ratio (as shown in Sect. 5.2). We use Kirchstetter et al. (2004) for our baseline refractive index of $\mathrm{BrC}$ because it provides reasonable maximum and median $f_{\mathrm{BrC}}$ and $\mathrm{BrC} / \mathrm{sC}$ ratios at the biomass burning sites.

Hematite also exhibits a large range of reported refractive indices, some of which are noted in Table 1. Hematite and goethite are the two dominant absorbers in mineral dust, and most of the spectral variability of dust absorption at visible wavelengths is associated with hematite. Consequently, we must choose hematite refractive indices for our retrieval that have enough spectral variability to describe all of the AERONET retrievals. That is, $k_{440} / k_{\text {rnir }}$ is often greater than 5 in the AERONET database, so we need to choose hematite and goethite optical properties that can accomplish this spec- 
tral variability. Since the only available goethite measurement has a positive spectral dependence (i.e., $\mathrm{d} k / \mathrm{d} \lambda>0$, per Bedidi and Cervelle, 1993), the hematite source that we choose must also indicate $k_{440} / k_{\text {rnir }}>5$.

Additionally, our choice of mineral refractive indices must produce retrieved hematite and goethite fractions that are consistent with other work. In situ measurements indicate that hematite and goethite constitute $2.8-6.5 \%$ of mineral dust by mass (Alfaro et al., 2004; Lafon et al., 2004, 2006; Wagner et al., 2012; Formenti et al., 2014). This corresponds to approximately $1.4-3.25 \%$ by volume, since the density of free iron is much greater than other common minerals $\left(4.28 \mathrm{~g} \mathrm{~cm}^{-3}\right.$ for goethite and $5.25 \mathrm{~g} \mathrm{~cm}^{-3}$ for hematite, as opposed to $2.65 \mathrm{~g} \mathrm{~cm}^{-3}$ for illite, kaolinite, quartz, and calcite; Formenti et al., 2014), Additionally, the hematite fraction of free iron ranges from 17 to $61 \%$ (Ji et al., 2002, 2004; Shi et al., 2012; Formenti et al., 2014).

We implemented the retrieval at the West African sites of Table 2, considering only "pure" dust (i.e., fine volume fractions less than 0.05 and depolarizations greater than 0.2 ), and present maximum and median results in Table 5. Here, we see that all of our candidate refractive indices for hematite produce median free iron and hematite fractions that are consistent with the in situ measurements, but only the Chen and Cahan (1981) refractive indices produce a maximum free iron fraction that is less than $3.5 \%$ by volume. Thus, we choose Chen and Cahan (1981) for our baseline retrieval, but we note that we have not scoured the literature for the most suitable hematite refractive index. The sensitivity of the results to our choice of refractive indices is discussed in the following two sections.

\subsection{Sensitivity of retrieved $\mathrm{sC}$ to other absorbers}

The $\mathrm{sC}$ results are shown in Fig. 11, which presents the relative mean biases with respect to the baseline value (i.e., $\overline{\mathrm{SC}} / \overline{\mathrm{sC}}_{\text {base }}$ ). The baseline retrieval is designated by the diamond in Fig. 11; it utilizes BrC refractive indices from Kirchstetter et al. (2004), hematite refractive indices from Chen and Cahan (1981), and sC refractive indices from Bond and Bergstrom (2006). We have included an additional six refractive indices for $\mathrm{sC}, \mathrm{BrC}$, and hematite (as listed in the lower portion of Table 1) and tested 18 combinations of these component refractive indices. All of the retrievals utilize Bedidi and Cervelle (1993) for the refractive index of goethite, since that is the only source available for this mineral.

There are six groups of bars in Fig. 11. Each group of bars utilizes the same $\mathrm{sC}$ and $\mathrm{BrC}$ refractive indices but different hematite refractive indices. Thus, the small variability of the bars within each group indicates that the choice of hematite refractive index (as indicated by color) has very little effect on the $\mathrm{sC}$ retrieval $(\lesssim 1 \%)$. There are two reasons for this: (1) the retrieval initially assumes that $\mathrm{sC}$ and hematite are located in different modes (i.e., fine vs. coarse), so the absorption interference associated with these species is minimized;

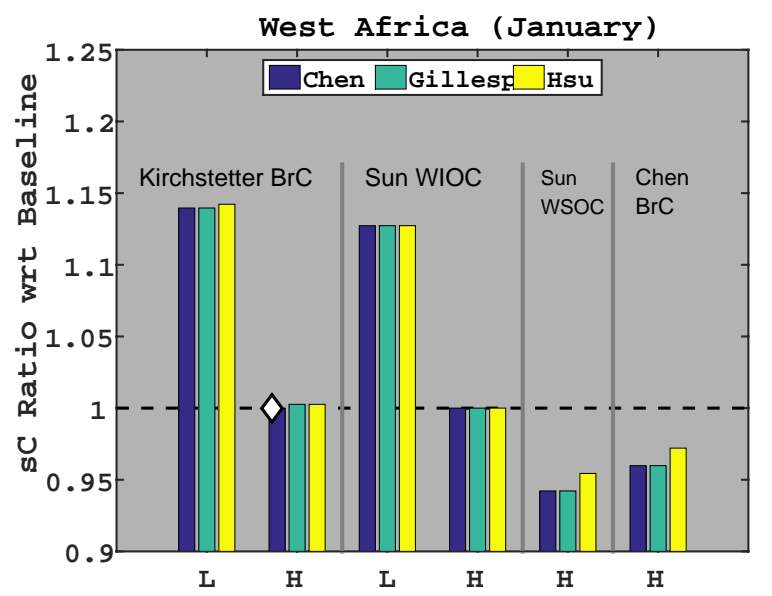

Figure 11. Relative bias associated with component refractive index uncertainty, utilizing 18 combinations of the refractive indices listed in Table 1. Each group of bars utilizes either the lowest (L) or highest $(\mathrm{H}) \mathrm{sC}$ refractive index recommended by Bond and Bergstrom (2006). Groups of bars are also labeled according to the four $\mathrm{BrC}$ refractive index sources in Table 1; color code denotes hematite refractive index source. Baseline components are denoted by the diamond. Note that the $\mathrm{sC}$ bias associated with refractive index uncertainty is always less than $15 \%$. See Table 1 for refractive index citations.

(2) the $\mathrm{SC}$ retrieval is mainly determined by the red and nearinfrared wavelengths, and hematite has a much lower imaginary refractive index than $\mathrm{sC}$ at those wavelengths.

The two leftmost groups of bars in Fig. 11 utilize the same $\mathrm{BrC}$ refractive indices (i.e., Kirchstetter et al., 2004), so the dominant difference between these two groups is caused by the different $\mathrm{SC}$ refractive indices used for the retrievals. Groups of bars labeled "L" utilize $m_{\mathrm{SC}}=1.75+0.63 i$, which is the low extreme from Bond and Bergstrom (2006); groups labeled " $\mathrm{H}$ " utilize $m_{\mathrm{SC}}=1.95+0.79 i$, the highest recommended value of Bond and Bergstrom (2006). Thus, the full range of $\mathrm{sC}$ refractive indices recommended by Bond and Bergstrom (2006) produces a sC retrieval uncertainty of $\leq 14.2 \%$.

We can assess the effect of $k_{\mathrm{BrC}}$ variability on the sC retrieval by observing all of the groups labeled " $\mathrm{H}$ " in Fig. 11. The retrievals in these four groups consistently use $k_{\mathrm{SC}}=$ 0.79 , and the color code corresponds to the hematite refractive index. Consequently, the only difference between likecolored bars in the " $\mathrm{H}$ " groups is the $\mathrm{BrC}$ refractive index. Thus, the dark blue bars indicate that using Sun et al. (2007) water soluble organic carbon for the $\mathrm{BrC}$ refractive index produces the maximal relative bias of $5.8 \%$ below our baseline Kirchstetter et al. (2004) retrievals.

Some authors expected this value to be substantially higher (e.g., Ganguly et al., 2009), but BrC does not appreciably absorb radiation at red or near-infrared wavelengths (Jacobson, 1999; Sato et al., 2003; Kanakidou et al., 2005). Hence, it is actually quite easy to separate the effect of $\mathrm{sC}$ 
Table 5. Volume fractions of hematite, goethite, and free iron for "pure" dust, and the volume percentage of iron associated with hematite $\left(\% H=V_{\text {hem }} /\left(V_{\text {hem }}+V_{\text {goe }}\right) \times 100\right)$ at the West African sites, using different refractive indices for hematite.

\begin{tabular}{lcccccccccc}
\hline & \multicolumn{4}{c}{ Maximums } & & \multicolumn{4}{c}{ Medians } \\
\cline { 2 - 4 } \cline { 9 - 11 } & $f_{\text {hem }}$ & $f_{\text {goe }}$ & $f_{\text {irn }}$ & $\% \mathrm{H}$ & & $f_{\text {hem }}$ & $f_{\text {goe }}$ & $f_{\text {irn }}$ & $\% \mathrm{H}$ \\
\hline Chen and Cahan (1981) & 0.009 & 0.029 & 0.034 & 93 & & 0.004 & 0.007 & 0.011 & 38 \\
Gillespie and Lindberg (1992) & 0.015 & 0.030 & 0.042 & 83 & & 0.008 & 0.008 & 0.016 & 50 \\
Hsu and Matijević (1985) & 0.025 & 0.030 & 0.052 & 84 & & 0.012 & 0.009 & 0.021 & 58 \\
\hline
\end{tabular}

from $\mathrm{BrC}$ using refractive indices at the $670-1020 \mathrm{~nm}$ wavelengths, since $\mathrm{sC}$ absorption is more than 2 orders of magnitude greater than $\mathrm{BrC}$ absorption in this spectral region (as shown in Fig. 1).

Overall, Fig. 11 indicates that relative bias in the $\mathrm{sC}$ retrieval ranges from -5.8 to $+14.2 \%$ at the African dust sites during the biomass burning season. The largest uncertainty is driven by the uncertainty in the $\mathrm{sC}$ refractive index. Uncertainty in the hematite refractive index has very little effect on the $\mathrm{sC}$ retrieval $(<1 \%)$, and uncertainty in the $\mathrm{BrC}$ refractive index alters the retrieval by less than $5.8 \%$. We also did a similar sensitivity study for the month of August at the biomass burning sites of South America (per Table 2) to determine performance when carbonaceous aerosols are the dominant particles, and we found that both $\mathrm{BrC}$ and hematite refractive index uncertainties alter the $\mathrm{sC}$ retrieval by less than $1 \%$ (not shown).

We are now in a position to estimate the uncertainty associated with retrieving $\mathrm{sC}$ mass from the AERONET products. Recall that the estimated uncertainty for the imaginary refractive index in the Level 2 AERONET products is $50 \%$ (Dubovik et al., 2000), and $\mathrm{sC}$ is linearly related to the imaginary index for internal aerosol mixtures when $\mathrm{SC}$ is the only absorber present (Schuster et al., 2005); thus, the $\mathrm{SC}$ uncertainty associated with the AERONET retrieval is also $50 \%$. The measured $\mathrm{sC}$ densities are well known $\left(1.8 \mathrm{~g} \mathrm{~cm}^{-3} \pm 6 \%\right.$, per Bond and Bergstrom, 2006), and we estimated a maximum $14.2 \%$ uncertainty associated with the $\mathrm{sC}, \mathrm{BrC}$, and free iron refractive indices above. Since the AERONET products are based upon radiances and optical depth measurements and do not depend upon the component densities or refractive indices, these are independent uncertainties that can be added in quadrature (Taylor, 1982). Thus, the RMS uncertainty in retrieving $\mathrm{sC}$ mass that is associated with the AERONET refractive indices, $\mathrm{sC}$ density, and the component refractive indices of $\mathrm{sC}$, hematite, and $\mathrm{BrC}$ is $\sqrt{50^{2}+6^{2}+14 \cdot 2^{2}}=52 \%$.

\subsection{Sensitivity of retrieved $\mathrm{BrC}$ and free iron to other absorbers}

We can apply a similar analysis to $\mathrm{BrC}$ and hematite using Fig. 12. The top panel indicates that $\mathrm{sC}$ and hematite refractive indices have a small effect on the $\mathrm{BrC}$ bias (because all of
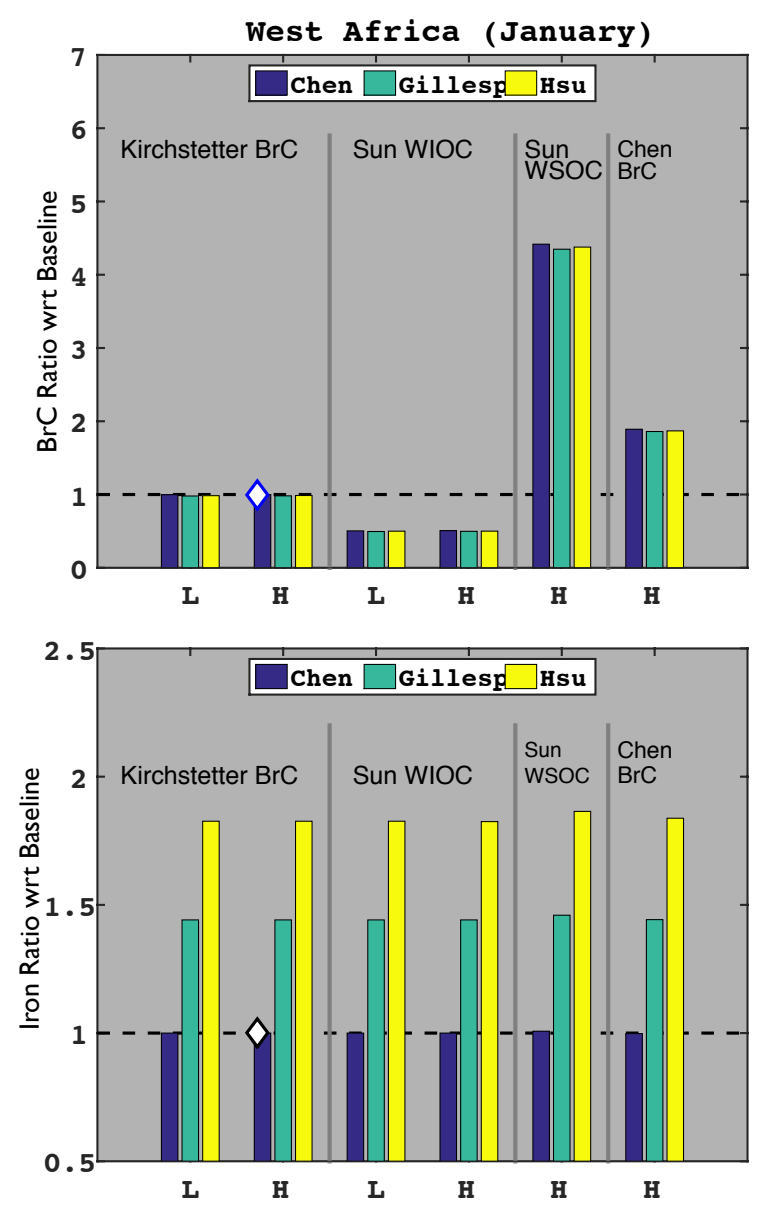

Figure 12. Same as Fig. 11, except $y$ axis is $\mathrm{BrC}$ (top panel) and free iron (bottom panel) relative biases.

the bars for a given $\mathrm{BrC}$ have similar magnitudes). However, the bias can be as low as $50 \%$ (using Sun et al., 2007, water insoluble OC for $\mathrm{BrC}$ ) or as high as $440 \%$ (using Sun et al., 2007, water soluble $\mathrm{OC}$ for $\mathrm{BrC}$ ). This is because the range of imaginary refractive indices for $\mathrm{BrC}$ varies by more than an order of magnitude at the $0.440 \mu \mathrm{m}$ wavelength (e.g., see Fig. 1), and this ambiguity propagates through the retrieval. Biases in our $\mathrm{BrC}$ retrieval could also occur whenever $\mathrm{NO}_{2}$ optical depths differ significantly from climatological values, but we do not attempt to quantify that here. 
The lower panel of Fig. 12 tells a similar story for iron. That is, all of the like-colored bars are similar in magnitude, indicating that the $\mathrm{SC}$ and $\mathrm{BrC}$ refractive indices have a relatively small effect on the amount of iron retrieved. However, the retrieval changes by $83 \%$ if we use the Kerker et al. (1979) refractive indices (as tabulated by Hsu and Matijević, 1985). It is doubtful that the various forms of hematite truly exhibit the large range of refractive indices found in the literature, though, and the remote sensing community could benefit from future work that narrows the range of plausible refractive indices for hematite. Since coarse mode iron is internally mixed with other minerals (Shi et al., 2012), we estimate the uncertainty associated with the free iron retrieval to be $\sqrt{50^{2}+83^{2}}=97 \%$.

\subsection{Uncertainty associated with incongruous retrieval assumptions}

Other possible errors associated with the AERONET product have already been described in Sect. 2. Some of these errors occur when conditions are not congruous with the retrieval assumptions, and these errors are very difficult to quantify. For instance, we stated earlier that the AERONET retrieval model assumes internal homogenous mixing for all aerosol particles; this could produce a bias in our $\mathrm{sC}$ retrievals if a significant portion of atmospheric $\mathrm{sC}$ is externally mixed. Schwarz et al. (2008) used a single-particle soot photometer (SP2) to determine the mixing state of $\mathrm{sC}$ and found that internal mixing occurred for $70 \%$ of the $\mathrm{sC}$ particles in fresh biomass burning plumes and $46 \%$ of the background $\mathrm{sC}$, but internal mixing only occurred for $9 \%$ of fresh urban emissions. Hence, although the internal mixing assumption required for the AERONET product might be reasonable in biomass burning regions, that assumption is less reliable in urban regions. Another unquantifiable error is the effect of using spheres and spheroids to approximate real particle shapes.

These are just two examples of errors that are known to exist but are extremely difficult to quantify in a realistic fashion. Uncertainty associated with ill-suited retrieval assumptions are endemic to all retrievals, though, and such errors escape the analysis provided by uncertainty propagation. However, in situ measurements are not immune to incongruous assumptions, either. Since quantifying the effect of inappropriate assumptions is not feasible, it is important to be mindful of the a priori assumptions when appraising the merit of any retrieval or measurement. Thus, we caution readers not to blindly interpret $\mathrm{sC}$ uncertainty estimates, both here and elsewhere in the literature.

\section{Conclusions}

We present a method of distinguishing the relative concentrations soot carbon $(\mathrm{sC})$, brown carbon, and free iron (hematite and goethite) aerosol species in the atmosphere. Our approach determines a mixture of absorbing and scattering aerosols that is consistent with the complex refractive indices provided by each AERONET retrieval. The method initially assumes that all carbonaceous aerosols are located in the fine aerosol mode, and all free iron is located in the coarse aerosol mode. However, the retrieval allows some carbonaceous aerosols to populate the coarse mode and some hematite to populate the fine mode (if this is necessary to reproduce the AERONET refractive indices). The solution for $\mathrm{sC}$ is unique because it is the only fine mode aerosol species with significant absorption at the red and near-infrared wavelengths. The solution for brown carbon and free iron is more ambiguous than the soot carbon retrieval, but the result for these other absorbers could be improved with better characterization of the refractive indices for those components.

The results show sensible regional and seasonal variability of the component aerosols, with the highest proportion of carbonaceous aerosols occurring at the seasonal biomass burning sites. The free iron mixing ratios and hematite/goethite ratios are also consistent with the values published in the scientific literature. We also present a sensitivity study, which indicates a $\sim 50 \%$ uncertainty in retrieved $\mathrm{SC}$ concentration that is mainly associated with the uncertainty of the refractive index in the AERONET products. Finally, since our mixtures maintain the AERONET internal homogeneous mixture assumption and are constrained by the AERONET refractive indices, our approach maintains a link to the measured radiance fields.

Acknowledgements. This material was supported by the National Aeronautics and Space Administration under the NASA Glory Science Team, issued through the Science Mission Directorate, Earth Science Division. Oleg Dubovik was supported by the Labex CaPPA project involving several research institutions in Nord-Pasde-Calais, France. Antti Arola acknowledges support from the Academy of Finland (through the project number 264242). We enjoyed informative discussions with Brent Holben and Tom Eck about the AERONET products, and we appreciate the efforts of the 29 AERONET and PHOTONS (Service d'Observation from LOA/USTL/CNRS) principal investigators and the entire AERONET and PHOTONS teams for obtaining, processing, documenting, and disseminating their respective data sets. We also appreciate the thorough efforts of the four expert reviewers, as their input greatly improved the final version of this paper. Finally, we acknowledge the efforts of Phillip Stier for overseeing the review process.

Edited by: P. Stier 


\section{References}

Alfaro, S., Lafon, S., Rajot, J., Formenti, P., Gaudichet, A., and Maille, M.: Iron oxides and light absorption by pure desert dust: an experimental study, J. Geophys. Res., 109, D08208, doi:10.1029/2003JD004374, 2004.

Andreae, M. O. and Gelencsér, A.: Black carbon or brown carbon? The nature of light-absorbing carbonaceous aerosols, Atmos. Chem. Phys., 6, 3131-3148, doi:10.5194/acp-6-3131-2006, 2006.

Arimoto, R., Balsam, W., and Schloesslin, C.: Visible spectroscopy of aerosol particles collected on filters: iron-oxide minerals, Atmos. Environ., 36, 89-96, 2002.

Arola, A., Schuster, G., Myhre, G., Kazadzis, S., Dey, S., and Tripathi, S. N.: Inferring absorbing organic carbon content from AERONET data, Atmos. Chem. Phys., 11, 215-225, doi:10.5194/acp-11-215-2011, 2011.

Bahadur, R., Praveen, P., Xu, Y., and Ramanathan, V.: Solar absorption by elemental and brown carbon determined from spectral observations, P. Natl. Acad. Sci. USA, 109, 17366-17371, doi:10.1073/pnas.1205910109, 2012.

Bedidi, A. and Cervelle, B.: Light scattering by spherical particles with hematite and goethitelike optical properties: effect of water impregnation, J. Geophys. Res., 98, 11941-11952, 1993.

Bohren, C. and Huffman, D.: Absorption and Scattering of Light by Small Particles, Wiley, New York, NY, USA, 1983.

Bond, T. and Bergstrom, R.: Light absorption by carbonaceous particles: an investigative review, Aerosol Sci. Tech., 40, 27-67, 2006.

Bond, T., Doherty, S., Fahey, D., Forster, P., Berntsen, T., DeAngelo, B., Flanner, M., Ghan, S., Kärcher, B., Koch, D., Kinne, S., Kondo, Y., Quinn, P., Sarofim, M., Schultz, M., Schulz, M., Venkataraman, C., Zhang, H., Zhang, S., Bellouin, N., Guttikunda, S., Hopke, P., Jacobson, M., Kaiser, J., Klimont, Z., Lohmann, U., Schwarz, J., Shindell, D., Storelvmo, T., Warren, S., and Zender, C.: Bounding the role of black carbon in the climate system: a scientific assessment, J. Geophys. Res., 118, 1-173, doi:10.1002/jgrd.50171, 2013.

Boucher, O., Randall, D., Artaxo, P., Bretherton, C., Feingold, G., Forster, P., Kerminen, V.-M., Kondo, Y., Liao, H., Lohmann, U., Rasch, P., Satheesh, S., Sherwood, S., Stevens, B., and Zhang, X.: Clouds and aerosols, in: Climate Change 2013: the Physical Science Basis. Contribution of Working Group I to the Fifth Assessment Report of the Intergovernmental Panel on Climate Change, edited by: Stocker, T. F., Qin, D., Plattner, G.-K., Tignor, M., Allen, S. K., Boschung, J., Nauels, A., Xia, Y., Bex, V., and Midgley, P. M., Cambridge University Press, Cambridge, UK, New York, NY, USA, 571-657, 2013.

Chakrabarty, R. K., Moosmüller, H., Chen, L.-W. A., Lewis, K., Arnott, W. P., Mazzoleni, C., Dubey, M. K., Wold, C. E., Hao, W. M., and Kreidenweis, S. M.: Brown carbon in tar balls from smoldering biomass combustion, Atmos. Chem. Phys., 10, 63636370, doi:10.5194/acp-10-6363-2010, 2010.

Chen, C. and Cahan, B.: Visible and ultraviolet optical properties of single-crystal and polycrystalline hematite measured by spectroscopic ellipsometry, J. Opt. Soc. Am., 71, 932-934, 1981.

Chen, Y. and Bond, T. C.: Light absorption by organic carbon from wood combustion, Atmos. Chem. Phys., 10, 1773-1787, doi:10.5194/acp-10-1773-2010, 2010.
Chung, C., Ramanathan, V., and Decremer, D.: Observationally constrained estimates of carbonaceous aerosol radiative forcing, P. Natl. Acad. Sci. USA, 109, 11624-11629, 2012.

Corrigan, C. E., Roberts, G. C., Ramana, M. V., Kim, D., and Ramanathan, V.: Capturing vertical profiles of aerosols and black carbon over the Indian Ocean using autonomous unmanned aerial vehicles, Atmos. Chem. Phys., 8, 737-747, doi:10.5194/acp-8-737-2008, 2008.

Derimian, Y., Karnieli, A., Kaufman, Y. J., Andreae, M. O., Andreae, T. W., Dubovik, O., Maenhaut, W., and Koren, I.: The role of iron and black carbon in aerosol light absorption, Atmos. Chem. Phys., 8, 3623-3637, doi:10.5194/acp-8-3623-2008, 2008.

Dinar, E., AboRiziq, A., Spindler, C., Erlick, C., Kiss, G., and Rudich, Y.: The complex refractive index of atmospheric and model humic-like substances (HULIS) retreived by a cavity ring down aerosol spectrometer (CRD-AS), Faraday Discuss., 137, 279-295, 2008.

Dubovik, O.: Photopolarimetry in Remote Sensing, chap. 3, pp. 65106, Kluwer Academic Publishers, Dordrecht, the Netherlands, 2004.

Dubovik, O. and King, M.: A flexible inversion algorithm for retrieval of aerosol optical properties from sun and sky radiance measurements, J. Geophys. Res., 105, 20673-20696, 2000.

Dubovik, O., Smirnov, A., Holben, B., King, M., Kaufman, Y., Eck, T., and Slutsker, I.: Accuracy assessments of aerosol optical properties retrieved from Aerosol Robotic Network (AERONET) sun and sky radiance measurements, J. Geophys. Res., 105, 9791-9806, 2000.

Dubovik, O., Holben, B., Eck, T., Smirnov, A., Kaufman, Y., King, M., Tanre, D., and Slutsker, I.: Variability of absorption and optical properties of key aerosol types observed in worldwide locations, J. Atmos. Sci., 59, 590-608, 2002a.

Dubovik, O., Holben, B., Lapyonok, T., Sinyuk, A., Mishchenko, M., Yang, P., and Slutsker, I.: Non-spherical aerosol retrieval method employing light scattering by spheroids, Geophys. Res. Lett., 29, 1415, doi:10.1029/2001GL014506, 2002b.

Dubovik, O., Sinyuk, A., Lapyonok, T., Holben, B.N., Mishchenko, M., Yang, P., Eck, T. F., Volten, H., Munoz, O., Veihelmann, B., van der Zande, W. J., Leon, J.-F., Sorokin, M., and Slutsker, I.: Application of spheroid models to account for aerosol particle nonsphericity in remote sensing of desert dust, J. Geophys. Res., 111, D11208, doi:10.1029/2005JD006619, 2006.

Formenti, P., Caquineau, S., Chevaillier, S., Klaver, A., Desboeufs, K., Rajot, J. L., Belin, S., and Briois, V.: Dominance of goethite over hematite in iron oxides of mineral dust from Western Africa: quantitative partitioning by X-ray absorption spectroscopy, J. Geophys. Res., 119, 12740-12754, doi:10.1002/2014JD021668, 2014.

Ganguly, D., Ginoux, P., Ramaswamy, V., Dubovik, O., Welton, J., Reid, E., and Holben, B.: Inferring the composition and concentration of aerosols by combining AERONET and MPLNET data: comparison with other measurementst and utilization to evaluate GCM output, J. Geophys. Res., 114, D16203, doi:10.1029/2009JD011895, 2009.

Garcia, O., Diaz, A., Exposito, F., Diaz, J., Dubovik, O., Dubuisson, P., Roger, J.-C., Eck, T., Sinyuk, A., Derimian, Y., Dutton, E., Schafer, J., Holben, B., and Garcia, C.: Validation of AERONET 
estimates of atmospheric solar fluxes and aerosol radiative forcing by ground-based broadband measurements, J. Geophys. Res., 113, D21207, doi:10.1029/2008JD010211, 2008.

Gillespie, J. and Lindberg, J.: Ultraviolet and visible imaginary refractive index of strongly absorbing atmospheric particulate matter, Appl. Optics, 31, 2112-2115, 1992.

Ginoux, P., Prospero, J., Gill, T., Hsu, N., and Zhao, M.: Globalscale attribution of anthropogenic and natural dust sources and their emission rates based on MODIS Deep Blue aerosol products, Rev. Geophys., 50, RG3005, doi:10.1029/2012RG000388, 2012.

Hand, V., Capes, G., Vaughan, D., Formenti, P., Haywood, J., and Coe, H.: Evidence of internal mixing of African dust and biomass burning particles by individual particle analysis using electron beam techniques, J. Geophys. Res., 115, D13301, doi:10.1029/2009JD012938, 2010.

Hashimoto, M., Nakajima, T., Dubovik, O., Campanelli, M., Che, H., Khatri, P., Takamura, T., and Pandithurai, G.: Development of a new data-processing method for SKYNET sky radiometer observations, Atmos. Meas. Tech., 5, 2723-2737, doi:10.5194/amt5-2723-2012, 2012.

Haywood, J., Francis, P., Dubovik, O., Glew, M., and Holben, B.: Comparison of aerosol size distributions, radiative properties, and optical depths determined by aircraft observations and sun photometers during SAFARI 2000, J. Geophys. Res., 108, 8471, doi:10.1029/2002JD002250, 2003.

Hoffer, A., Gelencsér, A., Guyon, P., Kiss, G., Schmid, O., Frank, G. P., Artaxo, P., and Andreae, M. O.: Optical properties of humic-like substances (HULIS) in biomass-burning aerosols, Atmos. Chem. Phys., 6, 3563-3570, doi:10.5194/acp-6-3563-2006, 2006.

Holben, B., Eck, T., Slutsker, I., Tanre, D., Buis, J., Setzer, A., Vermote, E., Reagan, J., Kaufman, Y., Nakajima, T., Lavenu, F., Jankowiak, I., and Smirnov, A.: AERONET - a federated instrument network and data archive for aerosol characterization, Remote Sens. Environ., 66, 1-16, 1998.

Holben, B., Tanre, D., Smirnov, A., Eck, T., Slutsker, I., Abuhassan, N., Newcomb, W., Schafer, J., Chatenet, B., Lavenu, F., Kaufman, Y., Castle, J. V., Setzer, A., Markham, B., Clark, D., Frouin, R., Halthore, R., Karneli, A., O’Neill, N., Pietras, C., Pinker, R., Voss, K., and Zibordi, G.: An emerging ground-based aerosol climatology: aerosol optical depth from AERONET, J. Geophys. Res., 106, 12067-12097, 2001.

Holben, B., Eck, T., Slutsker, I., Smirnov, A., Schafer, J., Giles, D., and Dubovik, O.: AERONET's Version 2.0 quality assurance criteria, in: Proc. SPIE, edited by: Tsay, S.-C., Nakajima, T., Singh, R., and Sridharan, R., vol. 6408, 64080Q, doi:10.1117/12.706524, 2006.

Hsu, W. and Matijević, E.: Optical properties of mondispersed hemitite hydrosols, Appl. Optics, 24, 1623-1630, 1985.

Jacobson, M.: Isolating nitrated and aromatic aerosols and nitrated aromatic gases as sources of ultraviolet light absorption, J. Geophys. Res., 106, 3527-3542, 1999.

Jacobson, M.: Short-term effects of controlling fossil-fuel soot, biofuel soot and gases, and methane on climate, Arctic ice, and air pollution health, J. Geophys. Res., 115, D14209, doi:10.1029/2009JD013795, 2010.

Ji, J., Balsam, W., Chen, J., and Liu, L.: Rapid and quantitative measurement of hematite and goethite in the Chinese loess-paleosol sequence by diffuse reflectance spectroscopy, Clay. Clay Miner., 50, 208-216, 2002.

Ji, J., Chen, J., Balsam, W., Lu, H., Sun, Y., and Xu, H.: High resolution hematite//goethite records from Chinese loess sequences for the last glacial-interglacial cycle: rapid climatic response of the East Asian Monsoon to the tropical Pacific, Geophys. Res. Lett., 31, L03207, doi:10.1029/2003GL018975, 2004.

Johnson, B., Christopher, S., Haywood, J., Osborne, S., McFarlane, S., Hsu, C., Salustro, C., and Kahn, R.: Measurements of aerosol properties from aircraft, satellite and ground-based remote sensing: A case-study from the Dust and Biomass-burning Experiment (DABEX), Q. J. Roy. Meteorol. Soc., 135, 922-934, 2009.

Kanakidou, M., Seinfeld, J. H., Pandis, S. N., Barnes, I., Dentener, F. J., Facchini, M. C., Van Dingenen, R., Ervens, B., Nenes, A., Nielsen, C. J., Swietlicki, E., Putaud, J. P., Balkanski, Y., Fuzzi, S., Horth, J., Moortgat, G. K., Winterhalter, R., Myhre, C. E. L., Tsigaridis, K., Vignati, E., Stephanou, E. G., and Wilson, J.: Organic aerosol and global climate modelling: a review, Atmos. Chem. Phys., 5, 1053-1123, doi:10.5194/acp-5-1053-2005, 2005.

Kandler, K., Benker, N., Bundke, U., Cuevas, E., Ebert, M., Knippertz, P., Rodriguez, S., Schütz, L., and Weinbruch, S.: Chemical composition and complex refractive index of Saharan mineral dust at Izaña, Tenerife (Spain) derived by electron microscopy, Atmos. Environ., 41, 8058-8074, 2007.

Kandler, K., Schütz, L., Deutscher, C., Ebert, M., Hofmann, H., Jäckel, S., Jaenicke, R., Knippertz, P., Lieke, K., Massling, A., Petzold, A., Schladitz, A., Weinzierl, B., Wiedensohler, A., Zorn, S., and Weinbruch, S.: Size distribution, mass concentration, chemical and mineralogical composition and derived optical parameters of the boundary layer aerosol at Tinfou, Morocco, during SAMUM 2006, Tellus B, 61, 32-50, 2009.

Kaufman, Y., Gitelson, A., Karnieli, A., Ganor, E., Fraser, R., Nakajima, T., Mattoo, S., and Holben, B. N.: Size distribution and scattering phase function of aerosol particles retrieved from sky brightness measurements, J. Geophys. Res., 99, 10341-10356, 1994.

Kerker, M., Scheiner, P., Cooke, D., and Kratohvil, J.: Absorption index and color of colloidal hematite, J. Colloid Interf. Sci., 71, 176-187, 1979.

Kim, D., Chin, M., Yu, H., Eck, T. F., Sinyuk, A., Smirnov, A., and Holben, B. N.: Dust optical properties over North Africa and Arabian Peninsula derived from the AERONET dataset, Atmos. Chem. Phys., 11, 10733-10741, doi:10.5194/acp-1110733-2011, 2011.

Kirchstetter, T., Novakov, T., and Hobbs, P.: Evidence that spectral dependence of light absorption by aerosols is affected by organic carbon, J. Geophys. Res., 109, D21208, doi:10.1029/2004JD004999, 2004.

Koch, D., Schulz, M., Kinne, S., McNaughton, C., Spackman, J. R., Balkanski, Y., Bauer, S., Berntsen, T., Bond, T. C., Boucher, O., Chin, M., Clarke, A., De Luca, N., Dentener, F., Diehl, T., Dubovik, O., Easter, R., Fahey, D. W., Feichter, J., Fillmore, D., Freitag, S., Ghan, S., Ginoux, P., Gong, S., Horowitz, L., Iversen, T., Kirkevåg, A., Klimont, Z., Kondo, Y., Krol, M., Liu, X., Miller, R., Montanaro, V., Moteki, N., Myhre, G., Penner, J. E., Perlwitz, J., Pitari, G., Reddy, S., Sahu, L., Sakamoto, H., Schuster, G., Schwarz, J. P., Seland, Ø., Stier, P., Takegawa, N., Takemura, T., Textor, C., van Aardenne, J. A., and Zhao, Y.: Eval- 
uation of black carbon estimations in global aerosol models, Atmos. Chem. Phys., 9, 9001-9026, doi:10.5194/acp-9-9001-2009, 2009.

Koven, C. and Fung, I.: Inferring dust composition from wavelength-dependent absorption in Aerosol Robotic Network AERONET data, J. Geophys. Res., 111, D14205, doi:10.1029/2005JD006678, 2006.

Lack, D., Richardson, M., Law, D., Langridge, J., Cappa, C., McLaughlin, R., and Murphy, D.: Aircraft instrument for comprehensive characterization of aerosol optical properties, Part 2: Black and brown carbon absorption and absorption enhancement measured with photo acoustic spectroscopy, Aerosol Sci. Tech., 46, 555-568, 2012.

Lafon, S., Rajot, J.-L., Alfaro, S., and Gaudichet, A.: Quantification of iron oxides in desert aerosol, Atmos. Environ., 38, 1211-1218, 2004.

Lafon, S., Sokolik, I., Rajot, J., Caquineau, S., and Gaudichet, A.: Characterization of iron oxides in mineral dust aerosols: implications for light absorption, J. Geophys. Res., 111, D21207, doi:10.1029/2005JD007016, 2006.

Leahy, L., Anderson, T., Eck, T., and Bergstrom, R.: A synthesis of single scattering albedo of biomass burning aerosol over southern Africa during SAFARI 2000, Geophys. Res. Lett., 34, L12814, doi:10.1029/2007GL029697, 2007.

Lesins, G., Chylek, P., and Lohmann, U.: A study of internal and external mixing scenarios and its effect on aerosol optical properties and direct radiative forcing, J. Geophys. Res., 107, 4094, doi:10.1029/2001JD000973, 2002.

Li, Z., Gu, X., Wang, L., Li, D., Xie, Y., Li, K., Dubovik, O., Schuster, G., Goloub, P., Zhang, Y., Li, L., Ma, Y., and Xu, H.: Aerosol physical and chemical properties retrieved from ground-based remote sensing measurements during heavy haze days in Beijing winter, Atmos. Chem. Phys., 13, 10171-10183, doi:10.5194/acp13-10171-2013, 2013.

Malm, W., Sisler, J., Huffman, D., Eldred, R., and Cahill, T.: Spatial and seasonal trends in particle concentration and optical extinction in the United States, J. Geophys. Res., 99, 1347-1370, 1994.

Martins, J., Artaxo, P., Liousse, C., Reid, J., Hobbs, P., and Kaufman, Y.: Effects of black carbon content, particle size, and mixing on light absorption by aerosols from biomass burning in Brazil, J. Geophys. Res., 103, 32041-32050, 1998.

Moosmüller, H., Chakrabarty, R., and Arnott, W.: Aerosol light absorption and its measurement: a review, J. Quant. Spectrosc. Ra, $110,844-878,2009$.

Myhre, G., Samset, B. H., Schulz, M., Balkanski, Y., Bauer, S., Berntsen, T. K., Bian, H., Bellouin, N., Chin, M., Diehl, T., Easter, R. C., Feichter, J., Ghan, S. J., Hauglustaine, D., Iversen, T., Kinne, S., Kirkevåg, A., Lamarque, J.-F., Lin, G., Liu, X., Lund, M. T., Luo, G., Ma, X., van Noije, T., Penner, J. E., Rasch, P. J., Ruiz, A., Seland, Ø., Skeie, R. B., Stier, P., Takemura, T., Tsigaridis, K., Wang, P., Wang, Z., Xu, L., Yu, H., Yu, F., Yoon, J.-H., Zhang, K., Zhang, H., and Zhou, C.: Radiative forcing of the direct aerosol effect from AeroCom Phase II simulations, Atmos. Chem. Phys., 13, 1853-1877, doi:10.5194/acp-13-18532013, 2013a.

Myhre, G., Shindell, D., Brèon, F.-M., Collins, W., Fuglestvedt, J., Huang, J., Koch, D., Lamarque, J.-F., Lee, D., Mendoza, B., Nakajima, T., Robock, A., Stephens, G., Takemura, T., and Zhang, H.: Anthropogenic and natural radiative forcing, in: Cli- mate Change 2013: The Physical Science Basis. Contribution of Working Group I to the Fifth Assessment Report of the Intergovernmental Panel on Climate Change, edited by: Stocker, T. F., Qin, D., Plattner, G.-K., Tignor, M., Allen, S. K., Boschung, J., Nauels, A., Xia, Y., Bex, V., and Midgley, P. M., Cambridge University Press, Cambridge, UK, New York, NY, USA, 659-740, $2013 b$.

Nakajima, T., Tanaka, M., and Yamauchi, T.: Retrieval of the optical properties of aerosols from aureole and extinction data, Appl. Optics, 22, 2951-2959, 1983.

Nakajima, T., Tonna, G., Rao, R., Boi, P., Kaufman, Y., and Holben, B.: Use of sky brightness measurements from ground for remote sensing of particulate polydispersions, Appl. Optics, 35, 26722686, 1996.

Park, R., Jacob, D., Chin, M., and Martin, R.: Sources of carbonaceous aerosols over the United States and implications for natural visibility, J. Geophys. Res., 108, 4355, doi:10.1029/2002JD003190, 2003.

Ramanathan, V. and Carmichael, G.: Global and regional climate changes due to black carbon, Nat. Geosci., 1, 221-227, doi:10.1038/ngeo156, 2008.

Reid, J., Jonsson, H., Maring, H., Smirnov, A., Savoie, D., Cliff, S., Reid, E., Livingston, J., Meier, M., Dubovik, O., and Tsay, S.-C.: Comparison of size and morphological measurements of coarse mode dust particles from Africa, J. Geophys. Res., 108, 8593, doi:10.1029/2002JD002485, 2003.

Reid, J. S., Eck, T. F., Christopher, S. A., Koppmann, R., Dubovik, O., Eleuterio, D. P., Holben, B. N., Reid, E. A., and Zhang, J.: A review of biomass burning emissions part III: intensive optical properties of biomass burning particles, Atmos. Chem. Phys., 5, 827-849, doi:10.5194/acp-5-827-2005, 2005a.

Reid, J. S., Koppmann, R., Eck, T. F., and Eleuterio, D. P.: A review of biomass burning emissions part II: intensive physical properties of biomass burning particles, Atmos. Chem. Phys., 5, 799825, doi:10.5194/acp-5-799-2005, 2005 b.

Sato, M., Hansen, J., Koch, D., Lacis, A., Ruedy, R., Dubovik, O., Holben, B., Chin, M., and Novakov, T.: Global atmospheric black carbon inferred from AERONET, P. Natl. Acad. Sci. USA, 100, 6319-6324, 2003.

Schafer, J., Eck, T., Holben, B., Thornhill, K., Anderson, B., Sinyuk, A., Giles, D., Winstead, E., Ziemba, L., Beyersdorf, A., Kenney, P., Smirnov, A., and Slutsker, I.: Intercomparison of aerosol single-scattering albedo derived from AERONET surface radiometers and LARGE in situ aircraft profiles during the 2011 DRAGON-MD and DISCOVER-AQ experiments, J. Geophys. Res., 119, 7439-7452, doi:10.1002/2013JD021166, 2014.

Schnaiter, M., Gimmler, M., Llamas, I., Linke, C., Jäger, C., and Mutschke, H.: Strong spectral dependence of light absorption by organic carbon particles formed by propane combustion, Atmos. Chem. Phys., 6, 2981-2990, doi:10.5194/acp-6-2981-2006, 2006.

Schuster, G.: Inferring the Specific Absorption and Concentration of Black Carbon from AERONET Aerosol Retrievals, PhD thesis, The Pennsylvania State University, available at: https://etda. libraries.psu.edu/paper/6233/ (last access: 14 January 2016), 2004.

Schuster, G. L., Dubovik, O., Holben, B. N., and Clothiaux, E. E.: Inferring black carbon content and specific absorption from 
Aerosol Robotic Network (AERONET) aerosol retrievals, J. Geophys. Res., 110, D10S17, doi:10.1029/2004JD004548, 2005. Schuster, G. L., Vaughan, M., MacDonnell, D., Su, W., Winker, D., Dubovik, O., Lapyonok, T., and Trepte, C.: Comparison of CALIPSO aerosol optical depth retrievals to AERONET measurements, and a climatology for the lidar ratio of dust, Atmos. Chem. Phys., 12, 7431-7452, doi:10.5194/acp-12-7431-2012, 2012.

Schuster, G. L., Dubovik, O., Arola, A., Eck, T. F., and Holben, B. N.: Remote sensing of soot carbon - Part 2: Understanding the absorption Ångström exponent, Atmos. Chem. Phys., 16, 15871602, doi:10.5194/acp-16-1587-2016, 2016.

Schwarz, J., Gao, R., Spackman, J., Watts, L., Thomson, D., Fahey, D., Ryerson, T., Peischl, J., Holloway, J., Trainer, M., Frost, G., Baynard, T., Lack, D., de Gouw, J., Warneke, C., and Negro, L. D.: Measurement of the mixing state, mass, and optical size of individual black carbon particles in urban and biomass burning emissions, Geophys. Res. Lett., 35, L13810, doi:10.1029/2008GL033968, 2008.

Schwarz, J., Spackman, J., Gao, R., Watts, L., Stier, P., Schulz, M., Davis, S., Wofsy, S., and Fahey, D.: Globalscale black carbon profiles observed in the remote atmosphere and compared to models, Geophys. Res. Lett., 37, L18812, doi:10.1029/2010GL044372, 2010.

Shi, Z., Krom, M., Jickells, T., Bonneville, S., Carslaw, K., Mihalopoulos, N., Baker, A., and Benning, L.: Impacts on iron solubility in the mineral dust by processes in the source region and the atmosphere: a review, Aeolian Res., 5, 21-42, 2012.

Smirnov, A., Holben, B., Eck, T., Dubovik, O., and Slutsker, I.: Cloud screening and quality control algorithms for the AERONET database, Remote Sens. Environ., 73, 337-349, 2000.
Sokolik, I. and Toon, O.: Incorporation of mineralogical composition into models of the radiative properties of mineral aerosol from UV to IR wavelengths, J. Geophys. Res., 104, 9423-9444, 1999.

Sun, H., Biedermann, L., and Bond, T.: Color of brown carbon: a model for ultraviolet and visible light absorption by organic carbon aerosol, Geophys. Res. Lett., 34, L17813, doi:10.1029/2007GL029797, 2007.

Taylor, J. R.: An Introduction to Error Analysis: The Study of Uncertainties in Physical Measurements, University Science Books, Oxford University Press, Mill Valley, CA, 1982.

Turpin, B. and Lim, H.-J.: Species contributions to $\mathrm{PM}_{2.5}$ mass concentrations: revisiting common assumptions for estimating organic mass, Aerosol Sci. Tech., 35, 602-610, 2001.

Wagner, R., Ajtai, T., Kandler, K., Lieke, K., Linke, C., Müller, T., Schnaiter, M., and Vragel, M.: Complex refractive indices of Saharan dust samples at visible and near UV wavelengths: a laboratory study, Atmos. Chem. Phys., 12, 2491-2512, doi:10.5194/acp-12-2491-2012, 2012.

Wang, L., Li, Z., Tian, Q., Ma, Y., Zhang, F., Zhang, Y., Li, D., Li, K., and Li, L.: Estimate of aerosol absorbing components of black carbon, brown carbon, and dust from ground-based remote sensing data of sun-sky radiometers, J. Geophys. Res., 118, 6534-6543, doi:10.1002/jgrd.50356, 2013.

Ziemba, L., Thornhill, K., Ferrare, R., Barrick, J., Beyersdorf, A., Chen, G., Crumeyrolle, S., Hair, J., Hostetler, C., Hudgins, C., Obland, M., Rogers, R., Scarino, A., Winstead, E., and Anderson, B.: Airborne observations of aerosol extinction by in situ and remote-sensing techniques: Evaluation of particle hygroscopicity, Geophys. Res. Lett., 40, 417-422, doi:10.1029/2012GL054428, 2013. 